\title{
Review
}

\section{Strategies for Safe and Effective Therapeutic Measures for Chronic Arsenic and Lead Poisoning}

\author{
Kiran KALIA $^{1}$ and Swaran J.S. FlorA ${ }^{2}$ \\ ${ }^{1}$ Department of Biosciences, Sardar Patel University and ${ }^{2}$ Department of Pharmacology and Toxicology, Defence \\ Research and Development Establishment, India
}

\begin{abstract}
Strategies for Safe and Effective Therapeutic Measures for Arsenic and Lead Poisoning: Kiran Kalia, et al. Department of Biosciences, Sardar Patel University, IndiaExposure to toxic metals remains a widespread occupational and environmental problem in world. There have been a number of reports in the recent past suggesting an incidence of childhood lead poisoning and chronic arsenic poisoning due to contaminated drinking water in many areas of West Bengal in India and Bangladesh has become a national calamity. Low level metal exposure in humans is caused by air, food and water intake. Lead and arsenic generally interferes with a number of body functions such as the central nervous system (CNS), the haematopoietic system, liver and kidneys. Over the past few decades there has been growing awareness and concern that the toxic biochemical and functional effects are occurring at a lower level of metal exposure than those that produce overt clinical and pathological signs and symptoms. Despite many years of research, we are still far from an effective treatment of chronic plumbism and arsenicosis. Medical treatment of acute and chronic lead and arsenic toxicity is furnished by chelating agents. Chelating agents are organic compounds capable of linking together metal ions to form complex ring-like structures called chelates. They have been used clinically as antidotes for acute and chronic poisoning. 2, 3-dimercaprol (BAL) has long been the mainstay of chelation therapy for lead or arsenic poisoning. Meso 2, 3, -dimercaptosuccinic acid (DMSA) has been tried successfully in animals as well as in a few cases of human lead and arsenic poisoning. DMSA could be a safe and effective method for treating lead or arsenic poisoning, but one of the major disadvantages of chelation with DMSA has been its
\end{abstract}

Received July 16, 2004; Accepted Oct 12, 2004

Correspondence to: S.J.S. Flora, Department of Pharmacology and Toxicology, Defence Research and Development Establishment, Jhansi Road, Gwalior-474 002, India

(e-mail: sjsflora@hotmail.com) inability to remove lead from the intracellular sites because of its lipophobic nature. Further, it does not provide protection in terms of clinical/ biochemical recovery. A new trend in chelation therapy is to use combined treatment. This includes the use of structurally different chelators or a combination of an adjuvant and a chelator to provide better clinical/ biochemical recovery in addition to lead mobilization. The present review article attempts to provide update information about the current strategies being adopted for a safe, effective and specific treatment for two major toxic metals or metalloid.

(J Occup Health 2005; 47: 1-21)

Key words: Chronic lead and arsenic poisoning, Oxidative stress, Chelation therapy, Drawbacks of chelation, New Chelating agents, DMSA monoesters, Combination Therapy, Biochemical changes, Herbal medicine

Exposure to toxic metals remains a widespread problem in most industrialised nations. Heavy metals generally interfere with a number of central nervous system (CNS), haematopoietic, hepatic and renal functions. Accumulated evidence shows that young children are more susceptible than adults to the deleterious effects of metals. Over the past few decades there has been growing awareness and concern that toxic biochemical and functional effects are occurring at lower levels of metal exposure than those that produce overt clinical and pathological signs and symptoms.

Oxidative stress has been reported as one of the important mechanisms in the toxic effects of heavy metals ${ }^{1)}$. The use of chelators for decreasing metal or metalloid toxicity started nearly $100 \mathrm{yr}$ ago with a collaboration between Alfred Werner in Zurich and Paul Ehrlich in Frankfurt, to find less toxic arsenic compounds for syphilis treatment. During 1920-1940, similar attempts were made to reduce the toxicity of arsenical drugs for trypanosomiasis by Voegtlin and antimony drugs for schistosomiasis ${ }^{2}$. 
British Anti-Lewisite (BAL) was one of the first chelating agents to be developed as an antidote for war gas, dichlorovinyl arsine (Lewisite) during the Second World War. The breakthrough in the development of chelation therapy came after the introduction of ethylene diamine tetraacetic acid (EDTA), initially to combat lead intoxication. The value of EDTA as a clinical chelating agent was reduced by the need for slow intravenous administration, low intestinal uptake, exclusive extracellular action and high stability constants with essential metals ${ }^{3)}$.

\section{Chelating agents and Chelation}

Chelating agents are organic compounds capable of linking together metal ions to form complex ring-like structures called 'chelates'. Chelate is a Greek word meaning the claws of a lobster. Chelators form a complex with the toxic metal ion and these complexes are easily eliminated from the body through the excretory system and also show low toxicity. The chemical affinity of the complexing agent for the toxic metal ion should be higher than the affinity of the metal for the sensitive biological molecules so that chemical measurement of the stability constants of the metal-complexes formed may give a first indication of the effectiveness of a particular chelating agent. An ideal chelating agent should possess such characteristic as greater affinity for the toxic metal that has to be chelated, low toxicity, rapid elimination of the metal, high water solubility, ability to penetrate cell membrane, oral administration, ability to chelate with natural chelating groups found in the biological system, and minimal metabolism, etc.

The metal chelate complexes have a reduced tendency to undergo exchange reactions once they are formed, but it is frequently advantageous to use a preferred donor atom in a chelating agent of lower density. It is also necessary to keep in mind that the introduction of the chelating agent into any intracellular space requires its passage through the cell membrane. This passage can be accomplished either (a) by passing through the lipid part of the membrane as an uncharged molecule or (b) by utilizing one of the anion/ cation transport systems present in the membrane ${ }^{4}$. There is a hypothesis that a large ion complex with a positive charge will pass out of a cell very slowly because of its inability to pass through either the lipid portion of the cellular membrane or the cation transport system designed to move ions with $\mathrm{a}+1$ or $\mathrm{a}+2$ charge across the membrane ${ }^{3,4)}$. Another important property of metal complexes is the stereochemistry of the toxic metal ion. Chelating agents tie up all the coordination positions of a metal ion ${ }^{5-10}$. Metal chelating agents generally contain more than one functional group, in order to provide a chemical claw to chelate the toxic metal.

\section{Conventional chelating agents and their drawbacks}

The most commonly used chelating agents that have been the forerunners in chelation therapy belong to the polyaminocarboxylic groups. As the name indicates, these chelators utilize the amino and the carboxylic groups to scavenge the toxic metal from the system. In this category, calcium disodium ethylene diamine tetra acetic acid $\left(\mathrm{CaNa}_{2}\right.$ EDTA) is a derivative of ethylene diamine tetra acetic acid (EDTA); a synthetic polyaminopolycarboxylic acid which was used for the treatment of metal poisoning and had been the mainstay of chelation therapy for many years. Another member of this family is diethylene triamine pentaacetic acid (DTPA), a synthetic polyaminocarboxylic acid with properties similar to EDTA ${ }^{11,12)}$. $\mathrm{CaNa}_{2}$ EDTA has the $\mathrm{LD}_{50}$ value of $16.4 \mathrm{mmol} / \mathrm{kg}$ in mouse ${ }^{13)}$. Intravenous administration of this drug results in good absorption but very painful at the injection site. Hence intravenous injection could be given either by diluting in $5 \%$ dextrose or saline ${ }^{14)}$. Hypocalcaemia is reported with the administration of $\mathrm{CaNa}_{2}$ EDTA. CaNa ${ }_{2}$ EDTA has the major toxic effects on the renal system causing the necrosis of tubular cells. Severe, hydropic degeneration of proximal tubule cells has also been reported. These lesions along-with some alterations in the urine such as hematuria, proteinuria and high BUN are generally reversible when the treatment ceases. Another side effect of EDTA is its ability to chelate various essential metals endogenous to the body, zinc in particular ${ }^{15,16)}$. Zinc administration during EDTA administration is generally recommended to reduce toxicity ${ }^{15)}$.

It has been well established that administration of EDTA during pregnancy can result in teratogenic effects especially when administered between days 11 to 14 at doses comparable to those for humans ${ }^{17,18)}$. 2-3\% disodium EDTA when given in feed along with $100 \mathrm{ppm}$ of zinc to pregnant rats from gestation day 6 through 21 resulted gross congenital malformations which included clubbed legs, micro or anophthalimia, micro or agnathia, cleft palate, fused or missing digits, brain malformation and curly, short or missing tail in the young ${ }^{19)}$. The use of EDTA to remove endogenous zinc appeared to offer a mechanism for studying the effects of short-term zinc supplementation at critical periods in pregnant zinc deficient rats. Kimmel showed that effects on teratogenicity varied with the route of administration of EDTA $^{20)}$. Subcutaneous administration of the disodium salt at a dose of $375 \mathrm{mg} / \mathrm{kg}$ was only maternally toxic, but did not cause any malformation, whereas gavage administration resulted in more signs of toxicity. Absorption into the circulation, potential interaction with essential trace elements, and the stress associated with the administration of the compound were suggested to be possible factors involved in the differences in EDTA- 
induced maternal and developmental toxicity ${ }^{20)}$. Brownie et al. also reported teratogenic effects ${ }^{17)}$. Another reported disadvantage of $\mathrm{CaNa}_{2}$ EDTA is that it redistributes lead to the brain. Cory Slechta et al. ${ }^{21)}$ and Flora et al. ${ }^{22)}$ in separate studies provided evidence that rats given lead as lead acetate in their drinking water and then treated with $\mathrm{CaNa}_{2}$ EDTA mobilized lead from their tissues and redistributed it to brain and liver on the first day of treatment. The large number of side effects due to the administration of these chelating agents prompted the commercialization of chelators containing thiol or sulfhydryl groups.

D-Penicillamine (DPA) is 3, 3 dimethylcysteine, a sulfhydryl containing amino acid, is as an antidote to low or mild lead poisoning ${ }^{23}$,24). It can penetrate cell membranes and then get metabolized. It can be absorbed through the gastrointestinal tract and therefore can be administered orally, but the major toxic effect of DPA is antagonizing pyridoxine and inhibiting pyridoxine dependent enzymes such as transaminases. Other toxic effects include hypersensitive allergic reactions such as fever, skin rashes, leucopoenia and thrombocytopenia ${ }^{26)}$. In few reports nephrotoxic effects have also been observed along with penicillin allergic reaction in sensitive individuals due to cross reactivity. Prolonged treatment may also lead to anorexia, nausea and vomiting in humans. Apart from this, DPA is also a well recognized teratogen and lathyrogen that causes skeletal, palatal, cutaneous and pulmonary abnormalities ${ }^{27-29)}$. The developmental toxicity of DPA is abundant in both humans and laboratory animals. The first report on human embryopathy associated with DPA was published by Mjolnerod et al. ${ }^{30)}$ Since DPA chelated copper, it was hypothesized that the drug might be teratogenic ${ }^{31)}$. Various investigations were performed in the early eighties to test the hypothesis ${ }^{31-34)}$ and a high incidence of malformations were reported. The frequency of reabsorption and the frequency and severity of malformations increased in the rats in a dose dependent manner ${ }^{33)}$. Nevertheless, the literature also suggests that the administration of DPA during pregnancy protects the mother from the relapse of Wilson's disease, whereas it would carry few risks to the fetus ${ }^{35}$. DPA has been tried safely throughout pregnancy in women with Wilson's disease, suggesting that the excessive copper stores improve tolerance ${ }^{36}$. The American Academy of Pediatrics recommends Penicillamine use only when unacceptable adverse reactions to both DMSA and EDTA have occurred ${ }^{37)}$, but Kreppel et al. reported that Penicillamine was ineffective in reducing arsenic burden in rats ${ }^{38)}$.

Meso 2, 3-dimercaptosuccinic acid (DMSA), is a water-soluble, sulfhydryl containing a compound which is an effective oral chelator for lead and arsenic. DMSA contains two sulfhydryl (-SH) groups and an analogue of dimercaprol. DMSA has been shown to be an effective chelator of lead, reducing blood lead levels significantly. Clinical symptoms and biochemical indices of lead toxicity also improved ${ }^{39,40)}$. Animal studies suggest that DMSA is an effective chelator of soft tissue but it is unable to chelate lead from bones ${ }^{22,41)}$. In an interesting study by Ercal et $a l$., lead induced biochemical variables suggestive of oxidative stress responded moderately to treatment with DMSA, and there was a marked reduction in the lead concentration in blood, liver and brain ${ }^{42}$. Miller suggested that the protocol for lead toxicity is to identify and remove the environmental exposure and use DMSA $10 \mathrm{mg} / \mathrm{kg}$ three times a day for the first five days followed by 14 days at $10 \mathrm{mg} / \mathrm{kg}$ twice a day ${ }^{43}$. DMSA has also been tried successfully in animals as well as in a few cases of human arsenic poisoning. DMSA has been shown to protect mice from the lethal effects of arsenic. We also reported a significant depletion of arsenic and a significant recovery in the altered biochemical variables of sub-chronically arsenic exposed rats ${ }^{44)}$. A number of other studies which appeared in the recent past have recommended that DMSA could be safe and effective for treating arsenic poisoning. But in an interesting perspective, a double blind randomized controlled clinical trial study conducted on a few selected patients from arsenic affected West Bengal, India regions with oral administration of DMSA suggested that DMSA was not effective in producing any clinical or biochemical benefits or any histopathological improvements in skin lesions ${ }^{45}$. Fournier et al. reported cases of heavy metal poisoning in humans who were treated with DMSA ${ }^{46)}$. In 9 subjects with lead poisoning DMSA decreased blood lead concentration by 35 to $81 \%$ and induced a 4.5 to 16.9 fold increase in mean daily urinary excretion of the metal. An experimental study by us recently provided in vivo evidence of arsenic induced oxidative stress in a number of major organs of arsenic exposed rats and that these effects can be mitigated by pharmacological intervention that encompasses combined treatment with nacetylcysteine and $\mathrm{DMSA}^{47)}$. In an interesting study reported by Tallis, three cases of acute lead arsenate poisoning in South Australia during a 12 month period were described $^{48)}$. The case reports provided a number of features of a characteristic clinical syndrome which may follow ingestion of lead arsenate. The patients were treated with EDTA and/ or BAL. The study suggests that lead poisoning could be effectively treated by EDTA but it is controversial as to whether chelation with dimercaprol prevents arsenical neuropathy. The above studies therefore in general recommend that DMSA has serious limitations in chelating arsenic from intracellular sites and can only be useful for acute cases of arsenic poisoning.

Sodium 2, 3-dimercaptopropane sulfonate (DMPS) is another analogue of BAL and is mainly distributed in the 
extracellular space and it may enter cells by means of a specific transport mechanism. DMPS is rapidly eliminated from the body through the kidneys. No major adverse effects after DMPS administration to humans or animals have been reported ${ }^{49)}$, but a dose dependent increase in copper content was found in the serum, liver, kidneys and spleen. Oral administration of DMPS also did not adversely affect late gestation, parturition or lactation in mature mice, and fetal and neonatal development do not appear to be adversely affected. DMPS, although known for its antidotal efficacy against mercury, has also been reported to be an effective drug for treating lead and arsenic poisoning ${ }^{50,51)}$. This drug can be administered both orally and intravenously. An oral dose of $100 \mathrm{mg} / \mathrm{kg}$ thrice daily for $10-12 \mathrm{~d}$ is effective against mild arsenic poisoning but no recommendation for treating chronic arsenic poisoning is available ${ }^{52)}$. A quantitative evaluation of three drugs reveals that DMPS is 28 times more effective than BAL in arsenic therapy in mice, and DMSA and DMPS are equally effective. Guha Majumder et al. evaluated the efficacy of DMPS in a single blind placebo control trial of patients suffering from chronic arsenic poisoning in West Bengal, India ${ }^{53)}$. DMPS was given in a $100 \mathrm{mg}$ capsule dose 4 times a day for $7 \mathrm{~d}$ for four courses with a one-week drug free period between courses. There was a significant decrease in clinical scores from pre-treatment to post treatment values amongst both DMPS and placebo groups. There was however, no change in skin histology, haematology and liver function test parameters in the patients before and after the therapy with DMPS or a placebo. And no side effects were noticed in patients treated with DMPS. Detailed toxic effects of the above-mentioned chelating agents have already being discussed by us in an earlier $\operatorname{article}^{54)}$.

It is therefore clear from the above that most of the conventional chelators are compromised with many side effects and drawbacks and there is no safe and effective treatment available for arsenic and lead poisoning. In the recent past some newer strategies were adopted to find a solution to this problem. In the following paragraphs some of these strategies have been discussed in brief.

\section{Synthesis of New Chelators}

In the early eighties it was shown that some newer complexing agents such as DMPS and DMSA were effective against arsenic and lead poisoning. When compared to BAL these newer chelating agents were of significantly lower toxicity and they could be administered orally or intravenously ${ }^{55)}$. In addition to their heavy metal chelating properties, these agents have a dithiol group that may act as an oxygen radical scavenger and thus inhibit lipid peroxidation ${ }^{56-58)}$.

\section{Esters of Succimer (DMSA)}

A large number of esters of DMSA have been synthesized for achieving optimal effects of chelation compared to DMSA. These esters are mainly the mono and dimethyl esters of DMSA that have been studied experimentally with the aim of enhancing tissue uptake of chelating agents ${ }^{59)}$. In order to make the compounds more lipophillic, the carbon chain length of the parent DMSA was increased by controlled esterification with the corresponding alcohol (methyl, ethyl, propyl, isopropyl, butyl, isobutyl, pentyl, isopentyl and hexyl). A large number of esters have been synthesized and are being tried for the treatment of metal poisoning. It has also been reported that these mono and diesters have a better potential in mobilizing cadmium and lead from the tissues of mice ${ }^{60,61,160)}$. Rivera et al. reported that the dimethyl ester of DMSA (meso-DiMeDMSA) increased the excretion of cadmium ${ }^{62)}$. They also reported that when rabbit liver metallothionein was incubated with the diester, $32 \%$ of the cadmium and $87 \%$ of zinc bound metallothionein was removed from the system ${ }^{63)}$. The diester entered the cells but it caused severe zinc depletion ${ }^{63)}$. Singh et al. examined the effects of three diesters of DMSA and found that these diesters were more effective than BAL in reducing soft organ lead concentrations ${ }^{64)}$. Kreppel et al. reported the therapeutic efficacy of six analogues of DMSA in mice ${ }^{65)}$. They gave mice a single $\mathrm{LD}_{80}$ dose of arsenic trioxide followed by a single dose of these six analogues of DMSA. They found that meso 2, 3-di (acetylthio) succinic acid (DATSA) and 2, 3-di (benzoylthio) succinic acid (DBTSA) increased the survival rates by $29 \%$ and $43 \%$ respectively when administered via a gastric tube (i.g) and $89 \%$ when administered intraperitoneally (i.p). Administration of dimethyl DMSA (DMDMSA) through i.g and i.p and diethyl DMSA (DEDMSA), di-n-propyl DMSA (DnPDMSA) and diisopropyl DMSA (DiPDMSA) through the i.g route did not reduce the lethality, whereas the i.p. administration of DnPDMSA increased the survival rate by $72 \%$ whereas DEDMSA and DiPDMSA increased it by $86 \%{ }^{65)}$. Kreppel et al. also reported the effects of 4 monoesters of DMSA in increasing the survival and arsenic elimination in various organs in mice ${ }^{66)}$. It was observed that all the monoesters, MiADMSA (mono- isoamyl), MnDMSA (mono n-amyl), MnBDMSA (mono n-butyl) and MiBDMSA (mono ibutyl) noticeable decreased the arsenic content in most of the organs as soon as $1.5 \mathrm{~h}$ after administration. They found that MiADMSA and MnADMSA were the most effective in increasing the survival of mice ${ }^{66)}$. We also performed similar studies where the effects of DMDMSA, DEDMSA DiPDMSA and diisoamyl DMSA (DiADMSA) on sub chronically arsenic treated rats were investigated ${ }^{44)}$. The results suggested that the diesters 
reduced the arsenic burden in blood and soft tissue but were only moderately effective in reversing the biochemical recovery when compared to DMSA ${ }^{44}$.

Walker et al. studied the effects of seven different monoalkyl esters of DMSA on the mobilization of lead in mice and observed that after a single parenteral dose of the chelator DMSA there was a $52 \%$ reduction in the lead concentrations whereas in the monoesters the reduction varied from $54 \%$ to $75 \%{ }^{61)}$. Jones et al. reported the efficacy of ten different monoesters through the oral and i.p. routes on cadmium mobilization in mouse ${ }^{60)}$. Out of the ten monoesters studied they found MiADMSA to be the most effective in reducing the cadmium concentrations in the liver and kidneys.

In most of these published reports, it has been observed that the analogues of DMSA were capable of crossing the membranes and were more effective than other analogues in reducing the metal burden in acute and subchronic metal intoxication. These studies have also suggested that the monoesters are more effective in the treatment of experimentally induced metal intoxication.

\section{Monoisoamyl DMSA (MiADMSA)}

Among these new chelators, monoisoamyl ester of DMSA (MiADMSA; a $\mathrm{C}_{5}$ branched chain alkyl monoester of DMSA) has been found to be the more effective than DMSA in reducing the cadmium and mercury burden ${ }^{67,68)}$. It is reported that the toxicity of DMSA with an $\mathrm{LD}_{50}$ of $16 \mathrm{mmol} / \mathrm{kg}$ is much lower than the toxicity of MiADMSA with an $\mathrm{LD}_{50}$ of $3 \mathrm{mmol} / \mathrm{kg}$ but less than BAL $(1.1 \mathrm{mmole} / \mathrm{kg})$. The interaction of MiADMSA and DMSA with essential metals is the same. Mehta and Flora reported for the first time the comparison of different chelating agents ( 3 amino and 4 thiol chelators) and their role in metal redistribution, hepatotoxicity and oxidative stress in chelating agents induced metallothionein in rats ${ }^{69)}$. We suggested that out of all the 7 chelators, MiADMSA and DMSA produced less oxidative stress and toxicity than 5 other chelators ${ }^{54)}$, but no major reports are available about the toxicity of this metal complexing agent except for its developmental toxicity. The no observed adverse effect levels (NOAELs) for maternal and developmental toxicity of MiADMSA were $47.5 \mathrm{mg} / \mathrm{kg}$ and $95 \mathrm{mg} / \mathrm{kg} / \mathrm{d}$, respectively, indicating that MiADMSA would not produce developmental toxicity in mice in the absence of maternal toxicity ${ }^{70)}$. Bosque et al. reported that administration of MiADMSA through the parenteral route to pregnant mice during organogenesis produced maternal toxicity at a dose of 95 and $195 \mathrm{mg} / \mathrm{kg}$ with a significant decrease in body weight and an increase in liver weight ${ }^{71)}$. They also reported that MiADMSA caused embryo/ fetotoxicity at a dose of $190 \mathrm{mg} / \mathrm{kg}$ by significantly increasing embryo lethality and a non-significant increase in skeletal defects. Taubeneck et al. showed that the developmental toxicity of DMSA is mediated mainly through disturbed copper metabolism and this may also be true for MiADMSA ${ }^{72}$. Recently, our group was the first to report the toxicological data on MiADMSA when administered in male and female rats ${ }^{73,74)}$ through the oral as well as the intraperitoneal route $(25,50$ and $100 \mathrm{mg} / \mathrm{kg} / 3 \mathrm{wk})$. We observed that there was no major alteration in the heme biosynthesis pathway except for a slight rise in the zinc protoporphyrin levels, suggesting mild anemia at the highest dose. The oral route of administration was also seen to be better than the ip route based on histopathological studies of liver and kidney tissues. MiADMSA was seen to be slightly more toxic in terms of copper loss and some biochemical variables in the hepatic tissue of females as compared to male rats. The studies concluded that the administration of MiADMSA to female rats is confounded with side effects and may require caution during its use $\mathrm{e}^{73,74)}$. Since administration of chelating agents during pregnancy always requires caution, we studied the effects of MiADMSA administration from day 14 of gestation to day 21 of lactation at different doses through oral and ip routes to examine the maternal and developmental toxicity in the pups $^{75)}$. Results suggested that MiADMSA had no effect on the length of gestation, litter-size, sex ratio, viability and lactation. And no skeletal defects were observed after the administration of the chelator. But, MiADMSA administration produced some marginal maternal oxidative stress at higher doses $(100 \mathrm{mg} / \mathrm{kg}$ and $200 \mathrm{mg} /$ $\mathrm{kg}$ ) based on thiobarbituric acid reactive substances (TBARS) in RBCs and a decrease in the $\delta$-aminolevulinic acid dehydratase (ALAD) activity. MiADMSA administration also caused some changes in the essential metal concentration in the soft tissues especially the copper loss in lactating mothers and pups, which would be of some concern. Apart from copper, changes were also observed in the zinc concentrations in mothers and pups after the administration of MiADMSA. The study further suggested that the chelator could be administered during pregnancy as it does not cause any major alteration in the mothers and the developing pups ${ }^{75}$. Since chelating agents are administrable to individuals of all ages, we investigated the effect of MiADMSA administration in different age groups of male rats (young, adult and old rats) based on the fact that whether MiADMSA, a dithiol agent, was a prooxidant or an antioxidant ${ }^{76)}$. Results suggested that MiADMSA administration increased the activity of ALAD in all the age groups and increased blood GSH levels in young rats. MiADMSA also potentiated the synthesis of MT in liver and kidneys and GSH levels in liver and brain. Apart from this it also significantly reduced the GSSG levels in tissues. MiADMSA was found to be safest in adult rats, followed by young and old rats ${ }^{77,158,159)}$.

A large number of reports are now available on the 
therapeutic efficacy of MiADMSA. Pande et al. found that MiADMSA was effective in the prevention and treatment of acute lead intoxication ${ }^{78)}$. Walker et al. reported that MiADMSA administration reduced brain lead concentrations by $75 \%$ when compared to $35 \%$ with DMSA, whereas ip administration reduced kidney lead levels by $93 \%$ whereas oral administration reduced kidney lead by $94 \%{ }^{61)}$. MiADMSA completely prevented testicular damage after intraperitoneal administration of cadmium chloride at a dose of $0.03 \mathrm{mmol} / \mathrm{kg}^{67}$.

Recently, Flora et al. reported the effect of MiADMSA on the reversal of gallium arsenide ( $\mathrm{GaAs}$ ) induced changes in hepatic tissue ${ }^{79,80)}$ Rats were exposed for 24 wk to $10 \mathrm{mg} / \mathrm{kg} \mathrm{GaAs}$, orally, once daily and treated with $0.3 \mathrm{mmol} / \mathrm{kg}$ of MiADMSA or DMSA for two courses. They observed that MiADMSA was better than DMSA in mobilizing arsenic and in the turnover of the GaAs sensitive biochemical variables. Histopathological lesions also responded more favorably to chelation therapy with MiADMSA. In another study, dose dependent therapeutic potential of MiADMSA was compared with monomethyl ester and DMSA in subchronically GaAs treated rats and it was found that MiADMSA was highly effective in the reversal of altered biochemical variables and in the mobilization of arsenic ${ }^{44)}$. We also reported the dose dependent effects of monoisoamyl and monomethyl esters of meso 2, 3dimercaptosuccinic acid (DMSA) $(0.1,0.3$ and $0.5 \mathrm{mmol} /$ $\mathrm{kg}$, i.p. once daily for 5 days) to offset the characteristic biochemical, immunological, oxidative stress consequences and DNA damage (based on DNA fragmentation and comet assay) after sub-chronic administration of gallium arsenide, and the mobilization of gallium and arsenic were examined. The study concluded that administration of DMSA monoesters (particularly MiADMSA) is of benefit in the removal of arsenic from gallium arsenide exposed rats, and recovery in some of the GaAs sensitive biochemical, immunotoxic variables and DNA damage, after 5 days of chelation therapy. We also recommended the use of MiADMSA for treating cases of GaAs intoxication for these reasons: (i) there was better recovery in the altered heme biosynthesis pathway (ii) better recovery in the tissue damage/oxidative stress, immunological variables and to some extend in DNA repair. Although, a significant recovery in the altered parameters indicative of oxidative stress, due to GaAs exposure could not be achieved, it may perhaps require two or three courses of 5 day treatment to achieve the optimum effects.

Dose and route dependent efficacy of MiADMSA against chronic arsenic poisoning has also suggested that the chelator is highly effective through the oral route in reversing the arsenic induced changes in the variables indicative of oxidative stress in major organs as well as in mobilization of arsenic ${ }^{81)}$. Kreppel et al. reported that
MiADMSA was more effective in increasing the survival of arsenic exposed mice than its parent $\mathrm{DMSA}^{66}$.

Despite a few drawbacks/side effects associated with MiADMSA, the above results suggest that MiADMSA may be a future drug of choice owing to its lipophilic character and the absence of any metal redistribution, but significant copper loss requires further study. Moderate toxicity after repeated administration of MiADMSA may be reversible after the withdrawal of the chelating agent.

\section{Natural Antagonists: Scavengers of Toxicity I: Role of Micronutrients}

Defense of the biological system against damage caused by activated oxygen involves a battery of interrelated protective agencies, the micronutrients, which have come to be regarded as antioxidant nutrients, lie functionally at the heart of this protective mechanism and include vitamins such as $\alpha$-tocopherol and ascorbic acid, etc. Antioxidants such as vitamins, when given either alone or in combination with a chelating agent, proved to be effective in mobilizing metal from soft as well as hard tissue. It is now well known that most of the heavy metals with special reference to lead and arsenic cause their toxicity due to the involvement of reactive oxygen species (ROS). These metals bind to biological molecules and produce different free radicals that in turn attack the building blocks of the biological systems. Impaired oxidant/ antioxidant balance can be partially responsible for the toxic effects of lead. The important role of heavy metals in oxidative damage suggested a new mechanism for an old problem, whether lead is involved in the oxidative deterioration of biological macromolecules. Several mechanisms have been proposed to explain the lead-induced toxicity ${ }^{82)}$. Recent studies suggest oxidative stress as one of the important mechanisms of the toxic effects of lead ${ }^{83)}$. Oxidative stress has also been seen to contribute to lead associated tissue injury in the liver, kidneys and brain ${ }^{84,85)}$. Indirect in vivo evidence of oxidative involvement in lead induced pathotoxicity was demonstrated by alleviation of oxidative stress in the erythrocytes after treatment with thiol containing proven antioxidants, $\mathrm{N}$-acetyl cysteine and a succimer in lead exposed rats ${ }^{83)}$. Deficiency of several essential nutrients namely vitamins and essential elements, has been shown to exacerbate the toxic effects of metals, and supplementation of such nutrients ameliorates the toxicity. In addition to the role of micronutrients in modifying metal toxicity, these nutritional components can also act as complimentary chelating agents (adjuvants) increasing the efficacy of a known chelator, or by acting independently ${ }^{161)}$.

\section{Calcium}

Interaction between lead and calcium occurs at several 
sites in the body, including cellular mechanisms that regulate ion transport across membranes ${ }^{86)}$. A significant increase in tissue lead, urinary delta-aminolevulinic acid (ALA) and renal intranuclear lead inclusion bodies was observed in lead exposed rats consuming low calcium ${ }^{87)}$. Silbergeld et al observed that calcium intake was negatively correlated with the blood lead level ${ }^{88)}$. Not many epidemiological data on the relationship between dietary calcium intake and the blood lead level in normal population groups are available. Kostial et al recommended adequate calcium $(940 \mathrm{mg} / \mathrm{d})$ especially for pregnant and lactating women (to prevent bone resorption) and for children (to enhance bone mass formation $)^{89)}$. Further work in this area will be useful particularly in view of a few recent reports in which it has been reported that coprophagy may be a serious complication in the rat model system as both calcium and lead may be recycled ${ }^{90)}$.

With a ligated isolated loop technique it was demonstrated that calcium intake rather than the calcium status of the animals modifies lead absorption ${ }^{91)}$. It is also clear that, atleast in part, calcium appears to inhibit lead absorption in competition for common binding sites on intestinal binding proteins.

\section{Iron}

Iron is a component of heme compounds which transport oxygen, cytochrome that functions in the electron transport chain and metalloprotein ${ }^{92,93)}$. Iron functions mainly in the regulation of oxidative processes. Subjects consuming a low iron diet had a tissue lead concentration significantly higher than subjects consuming adequate iron. Furthermore, excess iron uptake decreased blood, femur and kidney lead concentrations whereas low iron increased the tissue lead concentration ${ }^{94-98)}$. Rapid improvement in the development scores of infants after iron therapy has been reported $^{99)}$. The role of iron and lead in haem synthesis is well understood ${ }^{100)}$. The cellular basis for greater susceptibility of non-iron deficient animals to lead is that limited iron in the mitochondria apparently enhances the impairment by lead of iron utilization for heme synthesis beside the capacity of MT to attenuate the lead-induced inhibition of blood aminolevulinic acid dehydratase has also been reported ${ }^{101)}$. The existence of an MT-like protein in erythrocytes that binds lead and possibly protects against lead toxicity by rendering lead unavailable for retention in the target organs.

\section{Zinc}

Lead and zinc compete for similar binding sites in vivo, which might partially be responsible for atleast part of the protective effect of zinc on lead toxicity ${ }^{102)}$. Coadministration of zinc was found to effectively reverse, inhibition of the lead sensitive zinc dependent enzyme $\delta$-aminolevulinic acid dehydratase (ALAD) in male wistar rats ${ }^{103-105)}$. Victery et al. examined the excretion of lead, zinc and calcium in rats exposed to different levels of lead ${ }^{106)}$. Furthermore it has been demonstrated that low zinc intake exacerbates lead toxicity ${ }^{107)}$. The influence of orally supplemented zinc in preventing lead intoxication in laboratory animals has been reported by $u^{102)}$. In concomitant industrial exposure to both zinc and lead, it has been shown that zinc might activate the enzyme which masks the effect of lead ${ }^{108)}$. Therefore, the protective effect of zinc against lead toxicity could be attributed to a decrease in metal absorption in the gastrointestinal tract. Zinc could also be competing for and effectively reducing the availability of binding sites for trace metal uptake. Enhanced zinc also increases the renal and hepatic contents of metallothionein and causes detoxification through metal binding in this form.

Arsenic has also been shown to induce an increase in MT levels suggesting a possible role of this cysteine rich low molecular weight protein ${ }^{109)}$. There are also a few contradictory reports such as that of Kreppel et al. who reported that a zinc induced increase in MT does not seem to be responsible for the role of pre-administered zinc which protects against arsenic induced lethality ${ }^{110)}$. On the other hand there have been reports suggesting that zinc pre-treatment afforded an increase in arsenic elimination. We also recently reported that zinc either alone or in combination with monoisoamyl dimercaptosuccinic acid (DMSA) during and after arsenic exposure provided more pronounced elimination of arsenic in male mice ${ }^{111)}$. The data from the present study thus provide some new and interesting experimental evidence of a beneficial role of zinc supplementation in guarding against acute arsenic poisoning. Nevertheless, studies with variable doses of zinc particularly during chronic arsenic poisoning have been recommended in order to arrive at a final recommendation.

\section{Selenium}

Selenium, a required dietary element for health at low dose is an integral component of ubiquitous enzyme glutathione peroxidase, an antioxidant enzyme. This enzyme helps in neutralisation of reactive oxygen species (ROS). The role of selenium in lead intoxication has rather been controversial. Cerklewski and Forbes investigated the effect of low and high dietary selenium on toxicity of dietary lead in male rats and suggested that low dietary levels mildly protect against toxic effects of lead, but at high levels it exaggerates the lead toxicity ${ }^{112}$. Enzymatic activity of ALAD and Cytochrome P-450 in liver was normal in rats exposed concomitantly to selenium and lead ${ }^{113}$. We also suggested that oral administration of selenium could partly prevent lead toxicity during the course of simultaneous administration ${ }^{114)}$. Intramuscular injection of selenium 
prior to lead exposure provided prophylactic action against lead effects and we observed that selenium enhances the auto oxidant capacity of the cells by increasing the activity of the superoxide dismutase, glutathione reductase and glutathione content ${ }^{115}$.

Interaction of arsenic and selenium promotes the biliary excretion of exogenous selenium and selenite also augments the excretion of arsenic into bile ${ }^{116-118)}$. These authors suggested that arsenic augmented the hepatobiliary transport of selenium and facilitated accumulation of selenium in red blood cells. Selenium in turn facilitated the biliary excretion of arsenic. Glattre et al. studied the distribution and interaction of arsenic and selenium in rat thyroid and suggested that both arsenic and selenium accumulate in thyroid tissue ${ }^{119}$. Toxic changes were seen during post mortem examination, whereas only minor changes were observed in the selenium or arsenic plus selenium treated groups. We recently reported that selenium administration provided significant protection againt the liver injury caused by $\operatorname{arsenic}^{120)}$.

Competition between selenium and lead or arsenic for binding with the functional proteins and bioligand or active tissue sites or the formation of a reversible compound, metal-selenide thus reducing the availability of "free" concentrations of toxic metals ions in the body might be a possible mechanism for the observed antagonism between lead/ arsenic and selenium. The formation of metal-selenide may result from the interaction of metal and active selenium (selenide) released from in vivo reduction of administered sodium selenite $^{116,121)}$. Administration of selenium could provide a detoxifying action on metal ions, in addition to its antioxidant action ${ }^{162)}$. The need for selenium substitution in artificial nutrition is suggested and for this use selenomethionine appears to be the most suitable form.

\section{Copper}

Copper supplementation has also been shown to have some beneficial effects. Copper is a component of the mitochondrial electron transport chain and maintenance of neurotransmitter levels in the brain ${ }^{122,123)}$. Adequate intake of copper provides protection against lead, whereas higher intake of copper increases lead absorption ${ }^{124-127)}$.

The above studies clearly suggest that these micronutrients play a role in preventing toxic metal absorption and could also be co-administered during chelation therapy to maintain essential metal status during chelation treatment and could serve a dual purpose; i) to prevent possible essential metal deficiency syndrome and ii) to accelerate lead elimination due to their own antagonistic/biochemical/pharmacological effects ${ }^{128,163)}$. A beneficial role of zinc supplementation during lead chelation therapy has been reported ${ }^{15,129)}$. A more effective removal of hepatic and renal lead and recovery in the lead sensitive biochemical indices may offer an answer to the problem raised with $\mathrm{Ca}$ disodium EDTA (CaNa $\mathrm{CDTA}_{2}$ ) therapy ${ }^{21,22,130-133)}$. But we have cautioned against the excess and prolonged use of zinc, which may not allow the chelator to bind lead and rather zinc instead of lead ${ }^{15,129)}$. Thomas and Chisolm found that oral supplementation of zinc and copper salts during the course of $\mathrm{CaNa}_{2}$ EDTA treatment did not alter the urinary excretion of lead or zinc but reduced the fall in the plasma zinc concentration ${ }^{130)}$. The oral supplementation of zinc during chelation therapy has been found to be beneficial in a patient with plumbism ${ }^{133)}$, but simultaneous copper supplementation has a very limited role during chelation of lead ${ }^{134)}$.

\section{Scavengers of Toxicity II: Role of Antioxidants}

Induction of reactive oxygen species by metal and subsequent depletion of antioxidant cell defenses can result in disruption of the pro-oxidant/antioxidant balance in mammalian tissues. In the event that oxidative stress can be partially implicated in metal toxicity, a therapeutic strategy to increase the antioxidant capacity of cells may fortify the long-term effective treatment of metal poisoning. This may be accomplished by either reducing the possibility of metal interacting with critical biomolecules and inducing oxidative damage, or by bolstering the cells' antioxidant defenses through endogenous supplementation of antioxidant molecules. Although many investigators have confirmed lead induced oxidative stress, the usefulness of antioxidants along or in conjunction with chelation therapy has yet not been extensively investigated. Recently we have explored the therapeutic efficacy of an antioxidant along with a chelating agent during the removal of lead in rats ${ }^{78)}$. Some groups investigated the ability of some molecules with antioxidant activity to prevent or treat experimental lead toxicity in animals ${ }^{103,135-137)}$.

The following part mentions some of the forerunners in the list of antioxidants that have been tried in the treatment of metal poisoning, with special reference to lead and arsenic.

\section{A. Vitamins Thiamine}

Thiamine is one of the important vitamins which have been shown to afford significant protection against shortterm lead intoxication. Thiamine administered subcutaneously at a dose of $100 \mathrm{mg} /$ calf, decreased mortality and lead accumulation in various organs of calves $^{138)}$, but no beneficial effect on lead sensitive biochemical indices, e.g. blood ALAD, was noted in this study. Further studies suggested that thiamine initially facilitated absorption and an increase in the lead concentration in tissues and that thiamine may also promote a rapid release of lead from tissues ${ }^{139}$. A 
beneficial effect of dietary thiamine supplement on the tissue accumulation of lead, urinary excretion of ALA and inhibition of blood ALAD activity compared to rats fed a normal thiamine or a thiamine deficient diet was demonstrated by us ${ }^{140)}$. A few other studies reported that thiamine deficiency in the brain might be one of the factors contributing to increased sensitivity to seizure in lead exposed animals ${ }^{141}$. A protective mechanism, such as thiamine-lead complex formation was proposed. It was suggested that thiamine might facilitate the removal of lead from body fluids and other tissues by the formation of readily excretable complexes ${ }^{103,142-144)}$. Despite these encouraging reports, there are still no clinical reports available on the effect of dietary thiamine supplementation on lead toxicity. Thiamine as a complementary therapeutic agent or an 'adjuvant' to a conventional metal chelating agent has been tried ${ }^{145,146)}$. Thiamine administration concomitantly with $\mathrm{CaNa}_{2}$ EDTA enhanced the efficacy of a chelator to potentiate urinary lead excretion, to reduce tissue lead including brain lead and restore lead induced biochemical alterations ${ }^{147-150)}$. Thus, thiamine might be utilized to increase the passage of chelating agents through the blood brain barrier or to decorporate lead from the brain bioligand complexes ${ }^{149}$. Thiamine might also be participating in chelation as it contains a pyrimidine ring and a thiazole nucleus. The $\mathrm{OH}$ group of the side chain and $\mathrm{S}$ atom of the thizole nucleus from 2 moles of thiamine $\mathrm{HCl}$ may participate in the chelation of lead ${ }^{151)}$. Furthermore, N atoms or $\mathrm{NH}_{2}$ groups of the pyrimidine nucleus in the thiamine molecule might also play a role in the chelation of lead. Thiamine supplementations during chelation only slightly augmented lead decorporation but the depletion of brain lead was significant after treatment with thiamine DMSA $^{148,149)}$. These observations might be significant, as some of the chelators including $\mathrm{CaNa}_{2}$ EDTA have been shown to be ineffective in removing lead from the brain.

Ascorbic acid is another vitamin which has been studied extensively in modifying lead intoxication ${ }^{152,153)}$. Co administration of vitamin $\mathrm{C}$ and thiamine greatly enhanced the efficacy of chelating agents to increase urinary lead excretion, to reduce the tissue lead concentration including in the brain, supporting the view that ascorbic acid acts as a detoxifying agent by forming a poorly ionised but soluble complex with lead ${ }^{154-156)}$.

\section{Vitamin C (Ascorbic acid)}

Vitamin $\mathrm{C}$ is a low molecular mass antioxidant that interacts directly with the oxidizing radicals and protects the cells from reactive oxygen species ${ }^{157)}$. Vitamin C scavenges the aqueous reactive oxygen species (ROS) by very rapid electron transfer that thus inhibits lipid peroxidation $^{157,163,164)}$. It acts mainly as an antioxidant molecule and its beneficial effects could be attributed to its ability to complex with lead ${ }^{165,166)}$. Animal studies have suggested an antagonistic effect of ascorbic acid on lead absorption and toxicity and ascorbic acid may even chelate lead as effectively as EDTA ${ }^{154)}$, but studies on humans have shown some mixed results. In a study with 78 male workers, 38 received vitamin $\mathrm{C}$ and 38 were given a placebo ${ }^{167)}$. They found no effect of ascorbic acid on the absorption or excretion of lead, but 47 psychiatric patients receiving ascorbic acid and zinc had reduced blood lead concentrations ${ }^{168}$. Simon and Hudes investigated the association between the ascorbic acid concentration and the prevalence of a high blood lead concentration in 19, 578 participants aged $6 \mathrm{yr}$ and older in a National Health and Nutrition Examination Survey 1988-94 (NHANES III) ${ }^{169)}$. In a recently published study we reported some new interesting observations particularly the remarkable effects of combined treatment with vitamin $\mathrm{C}$ and succimer (DMSA or MiADMSA) on inhibited blood ALAD activity and in particular its beneficial effect in reducing arsenic induced oxidative stress. Co-administration of vitamin $\mathrm{C}$ and MiADMSA in reducing the liver and kidney arsenic burden supports the view that vitamin $\mathrm{C}$ acts as a detoxifying agent by forming a poorly ionized but soluble complex ${ }^{161)}$. Recently, a beneficial role of L-ascorbate coadministration against sodium arsenite in maintaining normal ovarian activity and brain monoamines was reported $^{170)}$.

\section{Vitamin E ( $\alpha$-tocopherol)}

Various vitamins have been found to reduce the toxic manifestation of lead ${ }^{154)}$. Dietary oral supplementation with these vitamins often lessens the severity of lead poisoning by inhibiting the lead absorption or interaction

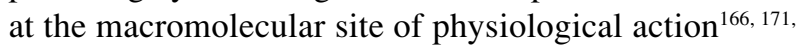
${ }^{182)}$. It also appears that the protective effect of vitamin $E$ in lead toxicity is attributed mainly to its antioxidant property ${ }^{172-174)}$. Vitamin E, which is a low molecular mass antioxidant, interacts directly with the oxidizing radicals and protects the cells from reactive oxygen species ${ }^{163,164,}$ 175, 176). Intramuscular administration of vitamin $\mathrm{E}$ prevented inhibition of blood ALAD activity, increase in urinary ALA excretion and was effective in reducing the lead induced altered biogenic amine levels in the brain during concomitant exposure to lead ${ }^{137)}$. Vitamin E supplementation during concomitant lead exposure also prevented lead deposition in liver and blood. Some of the protective effects of vitamin E also emerge directly from its antioxidant property and some through its influence on the drug metabolising enzyme system ${ }^{177,178)}$. Vitamin $E$ has also been reported to protect against $\operatorname{arsenic}^{179,180)}$. Addition of vitamin E may also alleviate arsenic toxicity. It was observed that vitamin E prevented the arsenite-induced killing of human fibroblasts ${ }^{179)}$. The protective mechanism of vitamin E could be attributed to its antioxidant property or its location in the cell 


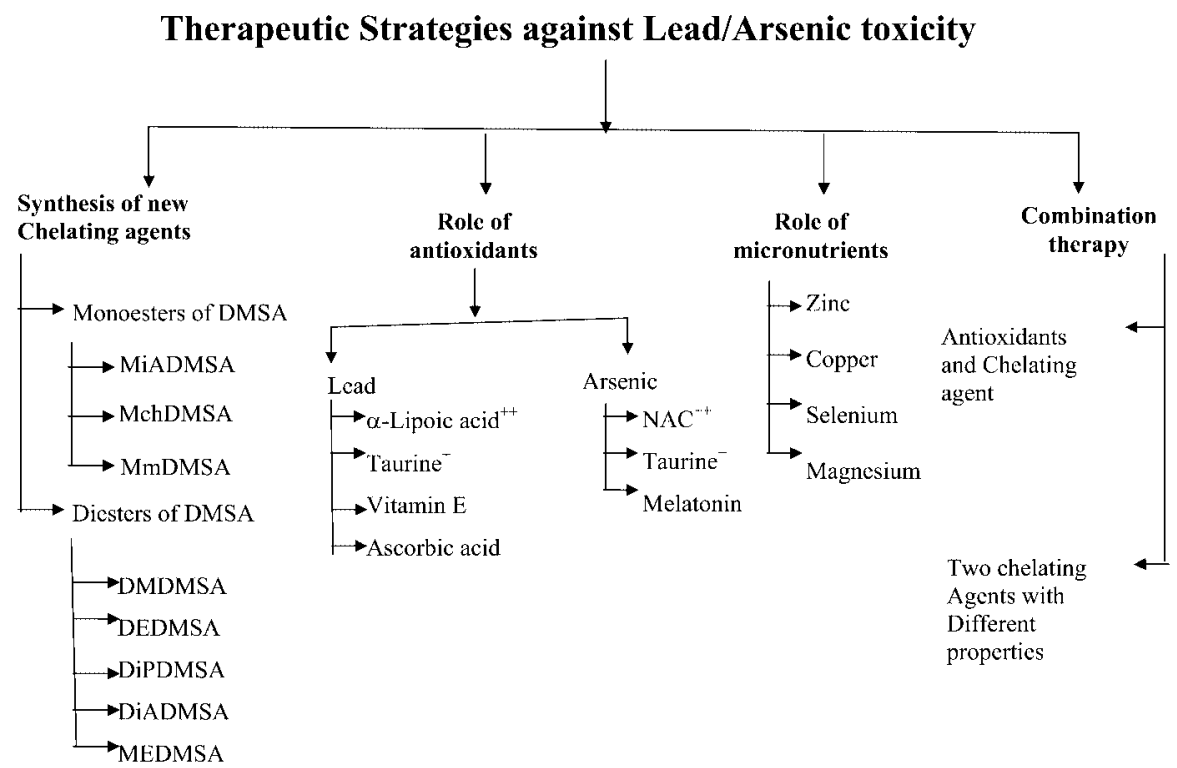

Fig. 1. List of newer strategies for lead and arsenic toxicity.

membrane and its ability to stabilize membrane by interacting with unsaturated fatty acid chain ${ }^{181)}$. Flora $e t$ al reported that administration of Vitamin $\mathrm{C}$ or vitamin $\mathrm{E}$ when given in combination with succimer or its monoisoamyl derivative (MiADMSA) produced profound recoveries in sub-chronically lead exposed rats $^{77)}$. Nevertheless, the group suggest that vitamin $\mathrm{C}$ was better in providing clinical recovery and Vitamin $\mathrm{E}$ was equally efficient in decreasing the lead burden on the tissues.

We also recently studied whether arsenic induced oxidative stress and the arsenic concentration in soft tissues could be more effectively reduced by some naturally occurring antioxidant such as vitamin $\mathrm{C}$ or vitamin $\mathrm{E}$ when given alone or in combination with DMSA or one of its analogues MiADMSA. The results lead us to suggest that co-administration of vitamins (vitamin $\mathrm{E}$ in particular) may be useful in the restoration of altered biochemical variables (particularly the effects on haem biosynthesis and oxidative injury) although it plays only a limited role in depleting the arsenic burden $^{183)}$.

\section{N-Acetylcysteine (NAC)}

NAC is a thiol-containing antioxidant that has been used to mitigate various degrees of oxidative stress. Its antioxidant action is believed to originate in its ability to stimulate GSH synthesis, therefore maintaining intracellular GSH levels and scavenging reactive oxygen species $(\mathrm{ROS})^{177,184)}$. Besides the antioxidant potential, NAC also has some chelating actions on lead ${ }^{185)}$. One of the first reports by Pande et al. suggested that NAC could be used both as a preventive as well as a therapeutic agent along with MiADMSA/DMSA in the prevention and treatment of lead intoxication in rats ${ }^{78)}$. Pande et al. reported that simultaneous administration of NAC with succimer reversed the altered ALAD and TBARS levels, increased the reduced glutathione levels and decreased the lead levels. Apart from this, the study also highlighted the favorable response of NAC in post-exposure treatment along with succimer ${ }^{78)}$. Combined administration of NAC and succimer after arsenic exposure led to a significant turnover in variables indicative of oxidative stress and removal of arsenic (Fig. 1) from soft organs ${ }^{186)}$. A recent report suggested that co-administration of NAC along with succimer in sub-chronically lead exposed rats, reduced oxidative stress significantly by lowering the TBARS levels, oxidized glutathione levels along with the decrease in the lead burden on the soft tissues, especially the brain ${ }^{187)}$.

\section{Melatonin}

Melatonin, N-acetyl-5-methoxy triptamine, is a hormonal product of the pineal gland that plays many roles within the body including control of reproductive functions, modification of immune system activity, and limitation of tumorigenesis and effective inhibition of oxidative stress ${ }^{188,189)}$. One major function of melatonin is to scavenge radicals formed in oxygen metabolism, thereby potentially protecting against free radical induced damage to DNA, proteins and membranes ${ }^{190-193)}$. It has been shown that melatonin stimulates the antioxidative enzyme GPx in the brain, thus providing indirect protection against free radical attack ${ }^{194)}$. In animal 
experiments, melatonin prevented the induction of free radical damage caused by a variety of conditions including ingestion of toxins, ionizing radiation, ischemia, reperfusion and excessive exercise ${ }^{192,195-198)}$. Melatonin has a molecular weight of 232 and is both lipid ${ }^{199,200)}$ and water soluble, although its solubility in lipid is clearly greater $^{201)}$. Therapeutic efficacy of melatonin either individually or in combination with succimer (DMSA) was recently studied by us in rats ${ }^{187)}$. We found very little role of melatonin in the mobilization of lead but it provided significant protection against lead induced oxidative stress in tissues of lead exposed rats.

\section{$\alpha$-Lipoic acid (LA)}

$\alpha$-Lipoic acid is a naturally occurring antioxidant and is able to abate some of the toxic effects of lead ${ }^{202)}$. It functions as a cofactor in several multienzyme complexes $^{203)}$. Its reduced form, dihydrolipoic acid (DHLA), has two free sulfhydryl groups and the two forms of LA/DHLA possess great antioxidant potential ${ }^{204}$. Both LA and DHLA (i) have the ability to scavenge some reactive species (ii) can regenerate other antioxidants (i.e. vitamins $\mathrm{E}$ and $\mathrm{C}$ and $\mathrm{GSH}$ ) from their radical or inactive forms, and (iii) have metal chelating activity. Lipoic acid also has an advantage over NAC in opposing GSH loss, since LA is effective in a micro molar range whereas mill molar NAC is needed for a similar effect ${ }^{205)}$. The capability of LA to cross the blood brain barrier is an extra advantage because the brain is an important target in lead poisoning ${ }^{206)}$. We provided experimental evidence of the beneficial effect of combined LA-succimers administration for treatment of sub-acute lead intoxication in rats. Administration of LA with DMSA or MiADMSA was most effective in reducing lead induced oxidative stress in brain compared to monotherapy ${ }^{207)}$. LA administration however, showed no chelating properties in decreasing the lead burden from blood and soft tissues except, interestingly, more pronounced decrease in the brain lead concentration in animals, LA plus thiol chelators, compared to the effect of thiol chelators. The mechanism for the beneficial effect of LA could be attributed to its ability to scavenge some reactive species, to regenerate other antioxidants and also, to some extent its moderate chelating property ${ }^{185)}$.

\section{Taurine}

Taurine a semi essential amino acid has been shown to play a role in maintaining calcium homeostasis, osmoregulation, removal of hypochlorous acid and stabilizing the membranes ${ }^{208,209)}$. Some recent data indicate that taurine can act as a direct antioxidant by scavenging ROS and/or as an indirect antioxidant by preventing changes in membrane permeability due to oxidant injury ${ }^{208)}$. The zwitterionic nature of taurine gives it high water solubility and low lipophilicity.
Consequently, compared with carboxylic amino acids, diffusion through lipophillic membranes is slow for taurine $^{210)}$. In the studies conducted by Gurer and Ercal, taurine was shown to have beneficial effects on lead induced oxidative stress in Chinese Hamster Ovary (CHO) cells and F344 rats ${ }^{177)}$. There was increased cell survival in taurine treated lead exposed CHO cells whereas MDA levels were diminished and GSH levels were increased. Similar effects were found in RBC and the brains and livers of lead exposed F-344 rats. In the above study, no chelating effect of taurine $(1.2 \mathrm{~g} / \mathrm{kg} / \mathrm{d})$ was indicated by any change in lead concentrations in the blood, brains, livers and kidneys after taurine treatment. An antioxidant mechanism, rather than a chelating activity, seems to underlie this observed effect of taurine on lead-induced oxidative stress. We recently described the dose dependent effect of taurine, either alone or in combination with meso 2, 3dimercaptosuccinic acid (DMSA) in the treatment of subchronic lead intoxication in male rats ${ }^{211)}$. The results suggested a beneficial role of taurine when administered along with DMSA in providing effective reversal of a number of lead sensitive biochemical variables in general, and parameters of oxidative stress in particular, compared to their individual effects. We noted a significant effect of taurine when co-administered with DMSA, in depleting blood and brain lead ${ }^{211)}$. It is known that the highest concentrations of taurine are in brain and heart. Perhaps this in part might explain the significant elimination of lead from the brain tissues. This is an interesting and significant observation which requires further exploration. The results thus lead us to conclude a beneficial role of taurine when administered along with a thiol chelator but still it remains to be seen if - (i) taurine is a better antioxidant than other available antioxidants in providing significant clinical recovery; (ii) a dose dependent study with a higher dose of taurine needs to be attempted; (iii) the exact mechanism of action of taurine needs to be elucidated.

The use of antioxidants thus brings another novel option to the therapy i.e. the possibility of therapeutic intervention without removing the patient from the source of lead. Antioxidants are recognized as safe molecules and may be given to subjects with low level lead concentrations in their blood even when it is not possible to remove them from exposure to lead.

\section{Combination therapy: A novel approach to the chelation of arsenic and lead}

A new trend in chelation therapy has also emerged recently, which is to use combination therapy instead of monotherapy with chelating agents. Vitamins, essential metals or amino acid supplementation during chelation therapy has been found to be beneficial in increasing metal mobilization and providing recovery in a number of 
altered biochemical variables. Combination therapy is a new and novel strategy. We have suggested in the earlier paragraphs that combined treatment with a chelating agent having an antioxidant property and a thiol chelator could be a better treatment protocol for lead poisoning than monotherapy with a chelator ${ }^{78,187)}$. The potential role of oxidative stress in injury associated with arsenic poisoning suggests that antioxidant may enhance the efficacy of the treatment protocol designed to mitigate arsenic induced toxicity. We have recently reported that combined administration of $n$-acetylcysteine and succimer led to a rapid mobilization of arsenic and lead, whereas administration of $\alpha$-lipoic acid and DMSA provided a more pronounced recovery in lead induced altered biochemical variables indicative of oxidative stress $^{78,186)}$. An experimental study conducted by us recently provided in vivo evidence of arsenic induced oxidative stress in a number of major organs of arsenic exposed rats and that these effects can be mitigated by pharmacological intervention that encompasses combined treatment with $\mathrm{N}$-acetylcysteine and $\mathrm{DMSA}^{186)}$. We also reported that co-administration of naturally occurring vitamins such as vitamin $\mathrm{E}$ or vitamin $\mathrm{C}$ during administration of a thiol chelator such as DMSA or MiADMSA may be more beneficial in the restoration of altered biochemical variables (particularly the effects on haem biosynthesis and oxidative injury) although it has only a limited role in depleting the arsenic burden. The study reports some new interesting observations, particularly the remarkable effects of combined treatment on inhibited blood ALAD activity and in particular its beneficial effect in reducing arsenic induced oxidative stress. Co-administration of vitamin $\mathrm{C}$ and MiADMSA in reducing the liver and kidney arsenic burden supports the view that vitamin $\mathrm{C}$ acts as a detoxifying agent by forming a poorly ionized but soluble complex ${ }^{169)}$.

\section{Combined administration of Two Chelating agents:}

We observed beneficial effects of MiADMSA in mobilizing arsenic from chronically pre-exposed GaAs and in reducing tissue oxidative stress, but it was observed that optimum effects of chelation therapy could be achieved by combined administration of oxalic acid and MiADMSA. Oxalic acid is an effective gallium chelator $^{77)}$. We also reported that combined administration of DMSA with calcium disodium EDTA decreases lead concentration in the brain ${ }^{22,51)}$. Besunder et al confirmed these studies in children and combination therapy with DMSA and EDTA for children hospitalized for chelation therapy is recommended instead of monotherapy with either agent ${ }^{160)}$. After some very positive results obtained with combined DMSA and EDTA administration for chronic lead poisoning, we compared the therapeutic efficacy of calcium disodium ethylenediaminetetracetic acid ( $\mathrm{CaNa}_{2}$ EDTA) with two different thiol chelators, 2, 3-dimercaptopropane 1-sulfonate (DMPS) and monoisoamyl dimercaptosuccinic acid (MiADMSA). The results of combined treatments with $\mathrm{CaNa}_{2}$ EDTA and the two thiols (DMPS and MiADMSA) were the more impressive, both in terms of recovery in altered biochemical variables (oxidative stress) and reduction of the body lead burden ${ }^{50)}$.

There have been recent debates about introducing a combined treatment therapy for lead poisoning ${ }^{22,88,89}$. The two arguments proposed for promoting this treatment point to the fact that (i) The inefficiency of EDTA to decrease brain lead and the ability of thiol chelators like DMSA for their reported role in promoting soft tissue lead mobilization including the brain (ii) addition of MiADMSA to EDTA caused not only higher lead elimination but also better recovery in altered biochemical variables. The studies done by us thus represent a systematic approach to the development of a new

\section{Benefits of proposed strategies}

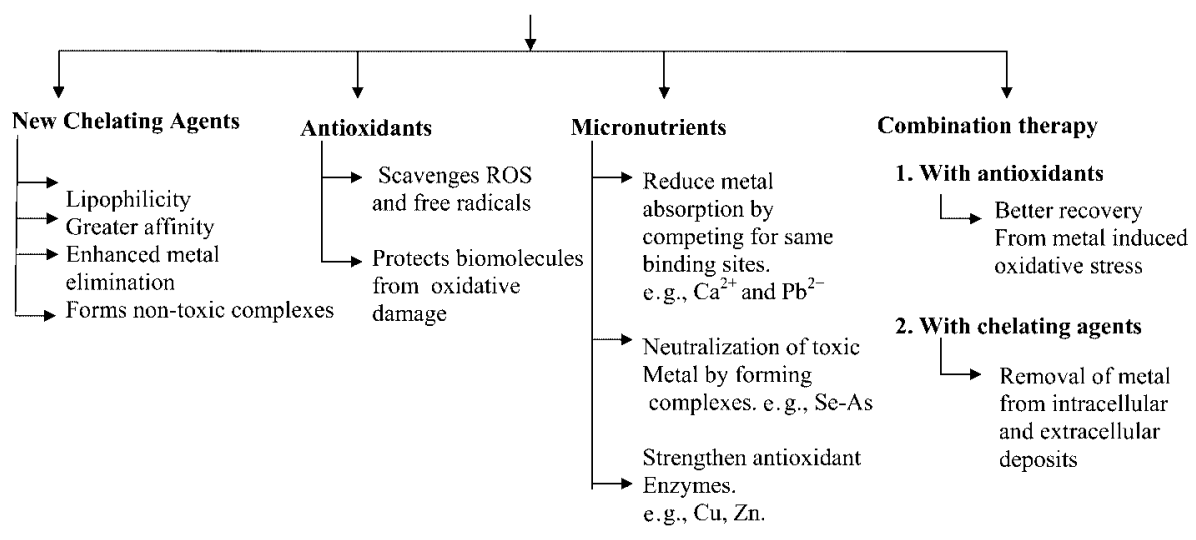

Fig. 2. Newer strategies for effective treatment of metal toxicity including beneficial effects. 
therapeutic protocol for the treatment of lead intoxication.

It is evident from the above that combination therapy is a new and a better approach to treat cases of metal poisoning, as only a little experimental evidence is available and there is a need for in depth investigation in this area.

With some very interesting results obtained with combined administration of two chelators for lead poisoning, it was proposed to investigate the effects of combination therapy for arsenic poisoning, where a strong chelating agent is administered along with another structurally different chelating agent ${ }^{22,158,159)}$. In a recent study we investigated whether co-administration of thiol chelators such as meso 2, 3-dimercaptosuccinic acid (DMSA) or sodium 2, 3-dimercaptopropane 1-sulfonate (DMPS) along with a newly developed thiol chelator, monoisoamyl DMSA, is more beneficial than monotherapy with these chelators in counteracting chronic arsenic toxicity ${ }^{159)}$. Animals were exposed to 10ppm arsenic in drinking water for 6 months and subsequently treated with two 5-day courses of chelation with DMSA, DMPS $(0.3 \mathrm{mg} / \mathrm{kg}$, i.p. once daily), or MiADMSA (0.1 mmole/kg, i.p. once daily) either individually or in combination. The data provided a promising role of combination treatment in potentiating the depletion of blood, liver, kidney and brain arsenic compared to monotherapy with these thiols (Fig. 2). It can be concluded from the study that concomitant administration of DMSA, an extracellularly distributed chelator with a lipophilic chelator such as MiADMSA, could play a significant and important role in abating the number of toxic effects of arsenic in animals compared to treatment with these chelators alone ${ }^{159)}$.

The outcomes of such studies, are important, especially in suggesting and developing new safe and highly effective control/ therapeutic measures to deal with cases of metal poisoning (particularly arsenic and gallium arsenide).

\section{Protective Efficacy of Various Plant Products on the Toxic Effects of Arsenic and Lead}

It is clear from the above, that most of the conventional metal chelating agents may have toxic side effects or disadvantages. The possibility of dietary intervention or supplementation of naturally occurring dietary nutrients to prevent the effects of arsenic in a population at risk is of interest ${ }^{69)}$. A positive correlation has also been established between dietary supplementation with a number of vegetables and plant parts and the reduction of toxic effects of many toxicants and environmental agents including heavy metals ${ }^{212}$. Concomitant administration of a few plant extracts such as Hippophae rhamnoides, Aloe Vera barbadensis and Centella asiatica either during exposure or during chelation treatment of the arsenic induced hematological, renal and hepatic disorders in laboratory animals have been found to be of some benefit ${ }^{213}$. Blood and liver arsenic concentrations also were determined but generally remained unaltered. Seabuckthorn (Hippophae rhamnoides, Elaegnaceae) is a thorny nitrogen fixing deciduous shrub, native to Europe and Asia ${ }^{214)}$. All parts of the plant are considered to be a good source of a large number of bioactive substances. The ripe fruit has been considered to be a rich source of Vitamin A, C, E, carotenoids and organic acids ${ }^{215}$, 216). Many medicinal effects of Seabuckthorn for flu, cardiovascular diseases, mucosal injuries and skin disorders have been reported to be due to the high content of antioxidant substances present in this plant ${ }^{217}$.

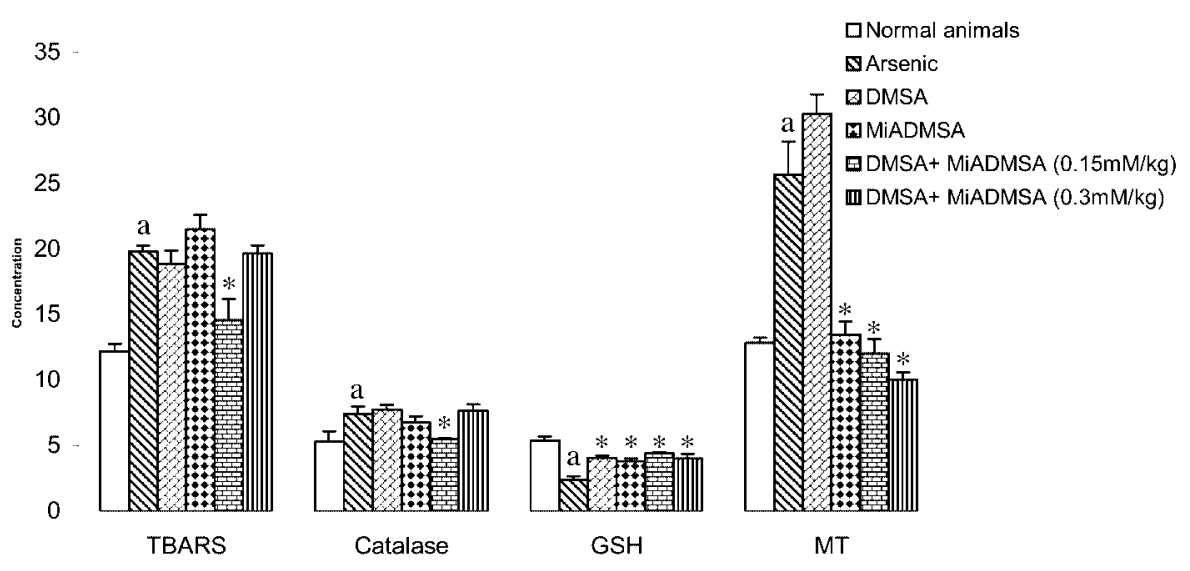

Fig. 3. Effect of combination therapy on hepatic oxidative stress in arsenic exposed rats. Units: TBARS in $\mu \mathrm{g} / \mathrm{g}$, Catalase in $\mathrm{M} / \mathrm{min} / \mathrm{mg}$ of protein, GSH in $\mathrm{mg} / \mathrm{g}$, MT in $\mu \mathrm{g} / \mathrm{g}$, Values are mean $\pm \mathrm{S}$. $\mathrm{E} ; \mathrm{n}=5$. aP $<0.05$ compared to normal; ${ }^{*} \mathrm{P}<0.05$ compared to arsenic exposed animals. 


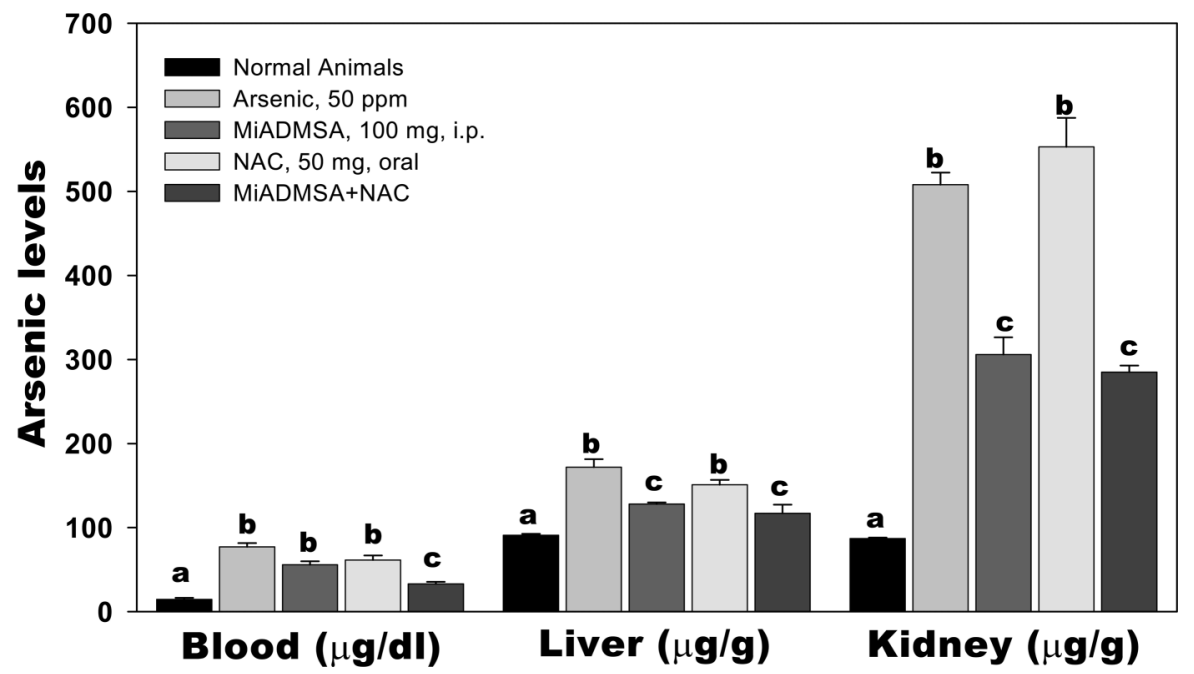

Fig. 4. Effect of combination therapy on arsenic concentration. Values are the means \pm S.E;

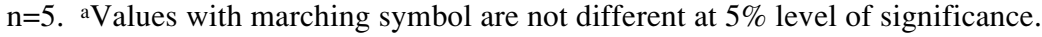

Recently, Geetha et al. have provided evidence in which the leaf extract of this plant has been found to have a potent oxidative stress action against chromium induced oxidative stress in rat ${ }^{218,219)}$. But no study is available on the protective role of Seabuckthorn against arsenic toxicity.

Aloe vera (Aloe barbadensis) is a tropical cactus, which has been reported to have a therapeutic potential in a variety of soft tissue injuries ${ }^{220}$. It has been used in the traditional medicine of many cultures and is said to be beneficial in the treatment of such disorders as arthritis, gout and dermatitis, etc and wounds such as peptic ulcer and burns. The fresh gel, juice or formulated products have been used for medical and cosmetic purposes and general health ${ }^{221,222)}$. In spite of its wide use in folk remedy over a long period, its effects on various heavy metals/ metalloid induced altered biochemical and physiological processes have not yet been described in detail and only a brief recent report suggests that it has some protective effects against arsenic induced oxidative stress.

In the Indian system of medicine Ayurveda, Centella asiatica (Umbelliferae) syn Hydrocotyl asiatica has been used in various parts of India for different ailments such as headache, body ache, insanity, asthma, leprosy, ulcers and wound healing ${ }^{223,224)}$. The whole plant of $C$. asiatica has been shown to be beneficial in improving memory and it is reported to improve the general mental ability of mentally retarded children ${ }^{225,226)}$.

It is therefore clear from the above that we are still far away from having a safe, specific and effective chelating agent for the treatment of metal poisoning. Apart from this, still further knowledge is needed in several basic research areas within the field of in vivo chelation of metals and there is a call for studies on (a) the molecular mechanism of action of clinically important chelators, (b) Intracellular and extracellular chelation in relation to the mobilization of aged metal deposits and the possible redistribution of toxic metal to sensitive organs as the brain, (c) Effect of metal chelators on biokinetics during continued exposure to metal, especially possible enhancement or reduction of intestinal metal uptake, (d) Combined chelation with lipophilic and hydrophilic chelators, which presently has a minimal clinical role, (e) Use of antioxidants, micronutrients or vitamins as complimentary agents or antagonists (f) Minimization of the mobilization of essential trace elements during longterm chelation, and (g) Fetotoxic and teratogenic effects of chelators (Figs. 3 and 4).

Acknowledgments: The authors thank Mr. K. Sekhar, Director of the establishment for his support and Ms Geetu Saxena, JRF for her efforts during the preparation of the manuscript.

\section{References}

1) K Kalia and KV Pavani: Metal-metal interaction- free radical formation as a mechanism of toxicity. J Pure Appl Sci Pragna 2, 1-5 (1993)

2) H Most: Drug therapy- treatment for common parasitic infection of man encountered in the United States. N Eng J Med 287, 698 (1972)

3) $\mathrm{AB}$ Fischer, $\mathrm{C}$ Hess, $\mathrm{T}$ Neubauer and T Eikmann: Testing of chelating agents and vitamins against lead toxicity using mammalian cell cultures. Analyst 123, 55-58 (1998)

4) Jones MM. Design of new chelating agents for removal of intracellular toxic metals. In: Kauffman GB, ed. 
Coordination chemistry: A century of progress. Amer Chem Soc, 1994: 427-438.

5) GJ Kontoghiorghes, L Sheppard and S Chambers: New synthetic approach and iron chelating studies on 1alkyl-2-methyl 3-hydroxyl pyrid-4-ones. Arzneim Forsch/Drug Res 37, 1099-1108 (1987)

6) RD Hancock and AE Martell: Ligand design for selective complexation of metal ion in aqueous solution. Chem Rev 89, 1875-1914 (1989)

7) RD Hancock: Molecular mechanics calculation and metal ion recognition. Acc Chem Res 23, 253-257 (1990)

8) DH Busch and NA Stephenson: Molecular organization, portal to supramolecular chemistry. Structural analysis of the factors associated with molecular organization in coordination and inclusion chemistry including the coordination template effects. Coord Chem Rev 100, 119-124 (1990)

9) LF Lindoy: The chemistry of macrocyclic ligand complexes. Cambridge University press, Cambridge (1989)

10) RM Izatt, K Pawlak, JS Bradshaw and RL Brevning: Thermodynamic and kinetic data for macrocycle interaction with cations and anions. Chem Rev 91, 1721-2085 (1991)

11) O Anderson: Principle and recent development in chelation treatment of metal intoxication. Chem Rev 99, 2683-2710 (1999)

12) M Forland, TN Pullman, AR Lavender and I Aho: The renal excretion of ethylenediamine tetraacetic acid in the dog. J Pharmacol Exp Ther 153, 142-147 (1966)

13) LR Cantilena Jr and CD Klaassen: Comparison of effectiveness of several chelators after single administration on the toxicity, excretion, and distribution of cadmium. Toxicol Appl Pharmacol 58, 452-460 (1981)

14) Klaassen CD. Heavy metals and heavy metal antagonist in Goodman and Gilman's. In: The Pharmacological Basis of Therapeutics. USA: Pergamon Press, 1990: 1592-1614 (1990).

15) SJS Flora and SK Tandon: Beneficial effects of zinc supplementation during chelation treatment of lead intoxication in rats. Toxicol 64, 129-139 (1990)

16) JJ Powell, TJ Burden, SM Greenfield, PD Taylor and RPH Thompson: Urinary excretion of essential metal following intravenous calcium disodium edetate: an estimate of free zinc and zinc status in man. J Inorg Biochem 75, 159-165 (1999)

17) CF Brownie, C Brownie, D Noden, L Krook, M Haluska and AL Aronson: Teratogenic effect of calcium edetate (CaEDTA) in rats and the protective effect of zinc. Toxicol Appl Pharmacol 82, 426-443 (1986).

18) H Tuchmann-Duplessis and L Mercier-Parort: Influence d'un corps de chelation l'acide ethylene diaminetetra acetique sur la gestation et le developmental fatal du rat. CR Acad Sci Paris 243, 1064 (1956)

19) SJS Flora and SK Tandon: Influence of calcium disodium edetate on the toxic effects of lead administration in pregnant rats. Ind J Physiol Pharmacol
31, 267-272 (1987)

20) CA Kimmel: Effect of route of administration on the toxicity of EDTA in the rat. Toxicol Appl Pharmacol 40, 299-306 (1977)

21) DA Cory-Slechta, B Weiss and C Cox: Mobilization and redistribution of lead over the course of calcium disodium ethylenediamine tetraacetate chelation therapy, J Pharmacol Exp Ther 243, 804-813 (1987)

22) SJS Flora, R Bhattacharya and R Vijayaraghavan: Combined therapeutic potential of meso 2, 3dimercaptosuccinic acid and calcium disodium edetate in the mobilization and distribution of lead in experimental lead intoxication in rats. Fund Appl Toxicol 25, 233-240 (1995)

23) JM Walshe: Pencillamine, a new oral therapy for Wilson's disease. Am J Med 21, 487 (1956)

24) WTL Ohlsson: Penicillamine as lead-chelating substance in man. BMJ ii, 1454-1456 (1962).

25) P Netter, B Bannwarth, P Pera and A Nicolas: Clinical pharmacokinetics of D-pencillamine. Clin Pharmacokinet 13, 317-333 (1987)

26) M Shannon, J Graef and FH Lovejoy: Efficacy and toxicity of D-penicillamine in low level lead poisoning. J Pediatr 112, 799-804 (1988)

27) RH Kilburn and RA Hess: Neonatal deaths and pulmonary dysplasia due to D-pencillamine in the rat. Teratology 26, 1-9 (1982)

28) B Myint: D-pencillamine-induced cleft palate in mice. Teratology 30, 333-340 (1984)

29) CG Roussaeux and LG MacNabb: Oral administration of D-pencillamine causes neonatal mortality without morphological defects in CD-1 mice. J Appl Toxicol 12, 35-38 (1992).

30) OK Mjolnerod, K Rasmussen, SA Dommerund and ST Gjerulsen: Congenital connective-tissue defect probably due to $\mathrm{D}$-pencillamine treatment in pregnancy. Lancet 1, 673-675 (1971).

31) Keen CL, Lonnerdal B, Hurley LS. Teratogenic effects of copper deficiency and excess. In: Sorenson JRJ, ed. Inflammatory diseases and copper. Clifton, NJ: The Humans Press, 1982: 109-121.

32) CL Keen, P Mark-Savage, B Lonnerdal and LS Hurley. Teratogenesis and low copper status resulting from DPenicillamine in rats. Teratology 26, 163-165 (1982)

33) CL Keen, P Mark-Savage, B Lonnerdal and LS Hurley: Teratogenic effects of D-pencillamine in rats. Relation to copper deficiency. Drug-Nutrient Interact 2, 17-34 (1983)

34) P Mark-Savage, CL Keen and LS Hurley: Reduction of copper supplementation of teratogenic effects of Dpencillamine. J Nutr 113, 501-510 (1983)

35) C Harvard and K Kunze: Pregnancy in a patient with Wilson's disease treated with D-pencillamine and zinc sulfate. A case report and review of literature. Eur Neurol 34, 337-340 (1994)

36) YK Soong, HY Huang, CC Huang and NS Chu: Successful pregnancy after D-pencillamine therapy in patients with Wilson's disease. J Formos Med Assoc 90, 693-696 (1991)

37) American Academy of Pediatrics. 1995. 
38) H Kreppel, FX Reichl, W Forth and B Fichtl: Lack of effectiveness of D-pencillamine in experimental arsenic poisoning. Vet Hum Toxicol 31, 1-5 (1989)

39) PB Hammond: Effect of chelating agents on the tissue distribution and excretion of lead. Toxicol Appl Pharmacol 18, 296-310 (1971)

40) JH Graziano, ES Siris, N LoIacono, SJ Silverberg and L Turgeon: 2, 3-dimercaptosuccinic acid as an antidote for lead intoxication. Clin Pharmacol Ther 37, 431438 (1985)

41) DA Cory-Slechta, B Weiss and C Cox: Mobilization and redistribution of lead over the course of calcium disodium ethylenediamine tetraacetate chelation therapy. J Pharmacol Exp Ther 243, 804-813 (1987)

42) N Ercal, P Treratphan, TC Hammond, RH Mathews, NH Grannemann and DR Spitz: In vivo indices of oxidative stress in lead exposed C57BL/6 mice are reduced by treatment with meso-2, 3dimercaptosuccinic acid or $\mathrm{N}$-acetyl cysteine. Free Rad Biol Med 21, 157-161 (1996)

43) AL Miller: Dimercaptosuccinic acid (DMSA), a nontoxic, water-soluble treatment for heavy metal toxicity. Altern Med Rev 3, 199-207 (1998)

44) SJS Flora, BP Pant, Neelima Tripathi, GM Kannan and DK Jaiswal: Distribution of arsenic by diesters of meso 2,3-dimercaptosuccinic acid during sub-chronic intoxication in rats. J Occup Health 39, 119-123 (1997)

45) DN Guha Mazumder, UC Ghoshal, J Saha, A Santra, BK De, A Chatterjee, S Dutta, CR Angle and JA Centeno: Randomized placebo-controlled trial of 2,3dimercapto succinic acid in therapy of chronic arsenicosis due to drinking arsenic contaminated subsoil water. Clin Toxicol 36, 683-690 (1998)

46) L Fournier, G Thomas, R Garnier, A Buisine, P Houze, F Pradier and S Dally: 2,3-dimercaptosuccinic acid treatment of heavy metal poisoning in humans. Med Toxicol Adverse Drug Exp 3, 499-504 (1988)

47) SJS Flora: Arsenic induced oxidative stress and its reversibility following combined administration of $\mathrm{N}$ acetyl cysteine and meso 2,3-dimercaptosuccinic acid in rats. Clin Exp Pharmacol Physiol 26, 865-869 (1999)

48) LA Tallis: Acute lead arsenate poisoning. Aust N Z J Med. 20, 750-751(1990)

49) K Hruby and A Donner: 2,3-dimercapto 1-propane sulfonate in heavy metal poisoning. Med Toxicol 2, 317-323 (1989)

50) G Saxena and SJS Flora: Lead induced oxidative stress and hematological alterations and their response to combined administration of calcium disodium EDTA with a thiol chelator in rats. J Biochem Mol Toxicol 18, 221-233 (2004)

51) SJS Flora, SN Dube, GM Kannan, Usha Arora and PR Malhotra: Therapeutic potential of meso 2,3dimercaptosuccinic acid and 2,3-dimercaptopropane 1sulfonate against chronic arsenic poisoning in rats. Biometals 8, 111-117 (1995)

52) Angle CR. Chelation therapies for metal intoxication. In: Chang LW, ed. Toxicology of Metals. CRC Press, 1996: 487-504.

53) DN Guha Mazumder, UC Ghoshal, J Saha, A De Santra,
A Chatterjee, S Dutta, CR Angle and JA Centeno: Randomized placebo-controlled trial of 2,3-dimercapto succinic acid in therapy of chronic arsenicosis due to drinking arsenic contaminated subsoil water. Clin Toxicol 36, 683-690 (1998)

54) Flora SJS, Dube SN, Tandon SK. Chelating agents and their use in metal poisoning. In: G Tripathi ed. Modern Trends in Environmental Biology, CBS Publisher. New Delhi, India, 2002: 209-227.

55) J Aaseth: Recent advances in the therapy of metal poisoning with chelating agents. Hum Toxicol 2, 257 272 (1983)

56) V Gersl, R Hrdina, J Vavrova, M Holeckova, V Palicka, J Vogkova, Y Mazurova and J Bajgar: Effects of repeated administration of dithiol chelating agentsodium 2,3-dimercapto 1-propanesulphonate (DMPS)on biochemical and hematological parameters in rabbits. Acta Medica 40, 3-8 (1997)

57) LC Benov, IC Benchev and $\mathrm{OH}$ Monovich: Thiol antidotes affect on lipid peroxidation in mercurypoisoned rats. Chem Biol Interact 76, 321-332 (1990)

58) LC Benov, SR Ribarov and OH Monovich: Studies of activated oxygen production by some thiol using chemiluminescences. Gen Physiology Biophys 11, 195-202 (1992)

59) Jones MM: Design of new chelating agents for removal of intracellular toxic metals. In: Kauffman GB, ed. Coordination chemistry: A century of progress. American Chemical Society, 1994: 427-438

60) MM Jones, PK Singh, GR Gale, AB Smith and LM Atkins: Cadmium mobilization in vivo by intraperitoneal or oral administration of mono alkyl esters of meso 2,3-dimercaptosuccinic acid. Pharmacol Toxicol 70, 336-343 (1992)

61) EM Walker, A Stone, LB Milligan, GR Gale, LM Atkins, AB Smith, MM Jones, PK Singh and MA Basinger: Mobilization of lead in mice by administration of monoalkyl esters of meso 2, 3dimercaptosuccinic acid. Toxicol 76, 79-87 (1992)

62) M Rivera, W Zheng, HV Aposhian and Q Fernando: Determination and metabolism of dithiol chelating agents VIII: metal complexes of meso dimercaptosuccinic acid. Toxicol Appl Pharmacol 100, 96-106 (1989)

63) M Rivera, DJ Levine, HV Aposhian and Q Fernando: Synthesis and properties of monomethyl ester of meso dimercaptosuccinic acid and its chelators of lead (II), cadmium (II), mercury (II). Chem Res Toxicol 4, $107-$ 114 (1991)

64) PK Singh, MM Jones, GR Gale, LM Atkins and AB Smith: The mobilization of intracellular cadmium by butyl and amyl esters of meso 2,3-dimercaptosuccinic acid. Toxicol Appl Pharmacol 97, 572-579 (1989)

65) H Kreppel, U Paepcke, H Thiermann, L Szinicz, FX Reichl, PK Singh and MM Jones: Therapeutic efficacy of new dimercaptosuccinic acid (DMSA) analogues in acute arsenic trioxide poisoning in mice. Arch Toxicol 67, 580-585 (1993)

66) H Kreppel, FX Reichl, A Kleine, L Szinicz, PK Singh and MM Jones: Antidotal efficacy of newly synthesized 
dimercaptosuccinic acid (DMSA) monoesters in experimental arsenic poisoning in mice. Toxicol Appl Pharmacol 26, 239-245 (1995)

67) $\mathrm{C} \mathrm{Xu}, \mathrm{MA}$ Holscher, MM Jones and PK Singh: Effect of monoisoamyl meso-2, 3-dimercaptosuccinate on the pathology of acute cadmium intoxication. J Toxicol Environ Health 45, 261-277 (1995)

68) GR Gale, AB Smith, MM Jones and PK Singh: Meso2, 3-dimercaptosuccinic acid monoalkyl esters: effects on mercury levels in mice. Toxicol 81, 49-56 (1993)

69) A Mehta and SJS Flora: Possible role of metal redistribution, hepatotoxicity and oxidative stress in chelating agents induced hepatic and renal metallothionein in rats. Fd Chem Toxicol 39, 10391043 (2001)

70) M Blanusa, L Prester, M Piasek, K Kostial, MM Jones and PK Singh: Monoisoamyl ester of DMSA reduces ${ }^{203} \mathrm{Hg}\left(\mathrm{NO}_{3}\right)^{2}$ retention in rats: 1 . Chelation therapy during pregnancy. J Trace Elem Exp Med 10, 173-181 (1997)

71) MA Bosque, JL Domingo, J Cobella, MM Jones and PK Singh: Developmental toxicity evaluation of monoisoamyl meso 2,3- dimercaptosuccinate in mice. J Toxicol Environ Health 42, 443-448 (1994)

72) MW Taubeneck, JL Domingo, JM Llobet and CL Keen: Meso 2,3-dimeracaptosuccinic acid (DMSA) affects maternal and fetal copper metabolism in swiss mice. Toxicol 72, 27-40 (1992)

73) A Mehta, GM Kannan, SN Dube, BP Pant, SC Pant and SJS Flora: Hematological, hepatic and renal alterations after repeated oral and intraperitoneal administration of monoisoamyl DMSA. Part I. Changes in male rats. J Appl Toxicol 22, 359-369 (2002)

74) SJS Flora and A Mehta: Haematological, hepatic and renal alterations after repeated oral and intraperitoneal administration of monoisoamyl DMSA. II. Changes in female rats. J Appl Toxicol 23, 97-102 (2003)

75) A Mehta and SJS Flora. MiADMSA and DMSA induced changes in pregnant female rats during late gestation and lactation. unpublished report.

76) Mehta A, Flora SJS: Prooxidant/Antioxidant effects of MiADMSA in male rats: age related effects. unpublished report.

77) SJS Flora, GM Kannan and BP Pant: Combined administration of oxalic acid, succimer and its analogue for the reversal of gallium arsenide induced oxidative stress in rats. Arch Toxicol 76, 269-276 (2002)

78) M Pande, A Mehta, BP Pant and SJS Flora: Combined administration of a chelating agent and an antioxidant in the prevention and treatment of acute lead intoxication in rats. Environ Toxicol Pharmacol 9, 173184 (2001)

79) SJS Flora, R Dubey, GM Kannan, RS Chauhan, BP Pant and DK Jaiswal: Meso 2, 3-dimercaptosuccinic acid (DMSA) and monoisoamyl DMSA effect on gallium arsenide induced pathological liver injury in rats. Toxicol Lett 132, 9-17 (2002)

80) SJS Flora, A Mehta, PVL Rao, GM Kannan, ASB Bhaskar, SN Dube and BP Pant: Therapeutic potential of monoisoamyl and monomethyl esters of meso 2,3- dimercaptosucccinic acid in gallium arsenide intoxicated rats. Toxicology 195, 127-146 (2004)

81) A Mehta, GM Kannan, SC Pant, SN Dube and SJS Flora: Dose and route related biochemical effects of monoisoamyl 2, 3 -dimercaptosuccinic Acid (MiADMSA) in male and female guinea pigs. J Tissue Research 3, 103-112 (2003)

82) L Tian and D Lowrence: Lead inhibits nitric oxide production in vitro by murine splenic macrophages. Toxicol Appl Pharmacol 132, 156-163 (1995)

83) H Gurer, H Ozgunes, R Neal, DR Spitz and N Ercal: Antioxidant effects of $\mathrm{N}$-acetyl cysteine and succimer in red blood cells from lead-exposed rats. Toxicol 128, 181-189 (1998)

84) B Halliwell: Free radicals, antioxidants and human disease: curiosity, cause and consequence. Lancet 344 , 721-724 (1994)

85) VN Adonaylo and PI OteizaI: Lead intoxication antioxidant defenses and oxidative stress in rat brain. Toxicol 135, 77-85 (1999)

86) JG Pound, GJ Long and JF Rosen: Cellular and molecular toxicity of lead bone Environ Health Perspect 91, 17-24 (1991)

87) MK Mahaffey-Six and RA Goyer: The influence of iron deficiency on tissue content and toxicity of ingested lead in the rat. J Lab Clin Med 79, 128-136 (1972)

88) EK Silbergeld, J Shwartz and KR Mahaffey: Lead and osteoporosis: mobilisation of lead from bone in postmenopausal women. Environ Res 47, 79-94 (1988)

89) K Kostial, D Dekanic, S Telisman, M Blanuska, S Duvanaic, D Prpic Majic and J Pongracic: Dietary calcium and blood levels in women. Biol Trace Elem Res 28, 181-185 (1991)

90) CS Fullmer: Lead-calcium interaction: involvement of 1, 25-dihydroxy vitamin D. Environ Res 72, 45-55 (1997)

91) JC Barton, ME Conrad, L Harrison and S Nuby: Effect of calcium on the absorption and retention of lead. $\mathrm{J}$ Lab Clin Med 91, 366-376 (1978)

92) RD Baynes and TH Bothwell: Iron deficiency. Ann Rev Nutr 10, 133-148 (1990)

93) CC McCormick: The tissue specific accumulation of hepatic zinc metallothionein following parental iron load. Proc Soc Exp Biol Med 176, 392-402 (1984)

94) KR Mahaffey: Environmental lead toxicity: nutrition as a component of intervention. Environ Health Perspect 89, 75-78 (1990)

95) Mahaffey KR. Nutrient lead interaction. In: Singhal RL, Thomas JA, eds. Lead Toxicity. Baltimore: Urbam and Schwarzenegger, 1980: 452-460.

96) DL Hamilton: Interrelationship of lead and iron retention in iron-deficiency mice. Toxicol Appl Pharmacol 46, 651-666 (1978)

97) PR Flanagan: Mechanism and regulation of intestinal uptake and transfer of iron. Acta Paediatric Scand Suppl 361, 21-30 (1989)

98) B Lozoff, GM Brittenham, FE Viteri, AW Wolf and JJ Urruita: The effect of short-term oral iron therapy on developmental deficits in iron deficient anaemic 
infants. J Pediat 100, 351-357 (1982)

99) FA Oski, AS Honig, B Hely and P Howanitz: Effects of iron therapy on behaviour performance in nonanaemic, iron deficient infants. Pediatrics 71, 877-880 (1983)

100) S Piomelli, C Seaman and S Kapoor: Lead induced abnormalities of porphyrin metabolism: the relationship with iron deficiency. Ann NY Acad Sci 514, 278-288 (1987)

101) PL Goering: Lead-protein interactions as a basis for lead toxicity. Neurotoxicol 14, 45-50 (1993)

102) SJS Flora, D Kumar and D Gupta: Interaction of zinc, methionine or their combination with lead at gastrointestinal or post-absorptive level in rats. Pharmacol Toxicol 68, 3-7 (1999)

103) SJS Flora, S Singh and SK Tandon: Thiamine and zinc in prevention or therapy of lead intoxication. J Inter Med Res 17, 68-75 (1989)

104) T Sakai, S Yanagihara and K Ushio: Restoration of lead-inhibited 5-aminolevulenate dehydratase activity in whole blood by heat, zinc ion and (or) dithiothreitol. Clin Chem 26, 625-631 (1980)

105) FL Cerklewski: Post-absorptive effect at increased dietary zinc on toxicity and removal of tissue lead in rats. J Nutr 114, 550-554 (1984)

106) W Victery, CR Miller and RA Goyer: Essential trace metal excretion from rats with lead exposure and during chelation therapy. J Lab Clin Med 107, 129-135 (1986)

107) $\mathrm{MH}$ Ashraf and GJ Fosmire. Effects of marginal zinc deficiency on sub-clinical lead toxicity in the rat neonate. J Nutri 115, 334-346 (1985)

108) EA Border, AC Cantrell and TA Kilroes-Smith. The in vitro effect of zinc on the inhibition of human $\delta$ aminolevulinic acid dehydratase by lead. Br J Indust Med 33, 85-87 (1976)

109) T Maitani, N Saito, M Abe, S Uchiyama and Y Saito: Chemical form-dependent induction of hepatic zincthionein by arsenic administration and effect of coadministrated selenium in mice. Toxicol Lett 39, 6370 (1987)

110) H Kreppel, J Liu, Y Liu, FX Reichl and CD Klaassen: Zinc-induced arsenite tolerance in mice. Fund Appl Toxicol 23, 32-37 (1994)

111) M Modi, U Pathak, K Kalia and SJS Flora: Coadministration of Zinc during Chelation of Arsenic with Monoisoamyl DMSA in Male Mice. Env Toxicol Pharmacol 19, 131-138 (2005)

112) FL Cerklewski and RM Forbes: Influence of dietary zinc on lead toxicity in rats. J Nutr 106, 689-696, 1976

113) SC Rastogi, J Clausen and KC Srivastava: Selenium and lead mutual detoxifying effects, Toxicol 6, 377378 (1976)

114) SJS Flora, S Singh and SK Tandon: Role of selenium in protection against lead intoxication. Acta Pharmacol et Toxicol 53, 28-32 (1983)

115) AI Othman and MA El-Missiry: Role of selenium against lead toxicity in male rats. J Biochem Molecul Toxicol 12, 345-349 (1998)

116) SJS Flora, GM Kannan and P Kumar: Selenium effects on gallium arsenide induced biochemical and immunotoxicological changes in rats. Chem Biol Interact 122, 1-13 (1999)

117) Magos L, Berg GG. Selenium. In: Clarkson TW, Friberg L, Nordberg GF, Sager PR, eds., Biological monitoring of toxic metals. Plenum: New York, 1988: 383.

118) A Gregus, A Gyurasics and L Koszorus. Interactions between selenium and group Va-metalloids (arsenic, antimony and bismuth) in the biliary excretion. Environ Toxicol Pharmacol 5, 89-99 (1998)

119) E Glattre, A Mravcova, J Lener, M Vobecky, E Egertova and M Mysliveckova: Study of distribution and interaction of arsenic and selenium in rat thyroid. Biol Trace Elem Res 49, 177-186 (1995)

120) M Modi, R Gupta and SJS Flora: Protective Value of Concomitant Administration of Trace Elements against Arsenic Toxicity in Mice. J Tissue Research 4, 257 262 (2004)

121) R Badiello, V Feroci and A Fini: Interaction between trace elements: selenium and cadmium ions. J Trace Elem Med Biol 10, 156-162 (1996)

122) Pike RL, Brown ML. Nutrition: An Integrated Approach, 3rd Edition, New York, John Wiley \& Sons: 1984: 167-200.

123) O Dell BL. Copper. In: Olson R, Broquist H, Chichester $\mathrm{C}$ et al., eds. Present knowledge in nutrition, 5th ed., Washington, DC: The Nutrition Foundation, Inc, 1984: 506-518.

124) GD Miller, TF Massaro and EJ Massaro: Interaction between lead and essential elements: A review. Neurotoxicol 11, 99-120 (1990)

125) DS Klauder and HG Petering: Protective value of dietary copper and iron against some toxic effects of lead in rats. Environ Health Persp 12, 77-80 (1975)

126) SJS Flora, JR Behari and SK Tandon: Protective role of trace metals in lead intoxication. Toxicol Lett 13: 51-56 (1982)

127) K Kalia, GS Shukla and SN Chandra: Lead and copper interaction: Hematocrit, ALAD and Cerruloplasmin in rats. Adv Biosci 3, 75-79 (1984)

128) MA Peraza, F Ayala-Fierro, DS Barber, E Casarez and LT Raei: Effect of micronutrients on metal toxicity. Environ Health Perspect 106, 203-216 (1990)

129) SJS Flora, R Bhattacharya and SRS Sachan: Dose dependent effects of zinc supplementation during chelation treatment of lead intoxication in rats. Pharmacol Toxicol 74, 330-333 (1994).

130) DJ Thomas and JJ Chisolm Jr: Lead zinc and copper decorporation during treatment of lead-poisoned children with calcium disodium ethylenediamineteraacetate, Toxicologist 6, 49 (abstract 191) (1996).

131) SJS Flora and P Kumar: Biochemical and Immunological evaluation of metal chelating drugs in rats. Drug Invest 5, 269-273 (1993)

132) VN Finelli, S Lerner, C Hong and C Lohiya: Effect of zinc supplementation during chelation therapy in plumbism. Med Lav 2, 149-156 (1980)

133) SJS Flora: Influence of simultaneous supplementation of zinc and copper during chelation of lead in rats. 
Human Exp Toxicol 10, 331-336 (1991)

134) SJS Flora, M Dhawan and SK Tandon: Influence of copper supplementation during chelation of lead. Clin Chem Enzymol Commun 3, 97-105 (1990)

135) SK Tandon, SJS Flora and S Singh: Chelation in metal intoxication XXIV: Influence of various components of Vitamin B complex of therapeutic efficacy of disodium calcium versenate in lead intoxication. Pharmacol Toxicol 60, 62-65 (1987)

136) $C$ McGowan: Influence of vitamin $B_{6}$ status on aspects of lead poisoning in rats. Toxicol Lett 47, 87-93 (1989)

137) M Dhawan, SJS Flora and SK Tandon: Preventive and therapeutic role of vitamin $\mathrm{E}$ in chronic plumbism, Biomed Environ Sci 2, 335-341 (1989)

138) GR Bratton, J Zmudzki, MC Bell and LC Warnock: Thiamin (Vitamin B1) effects on lead intoxication and deposition of lead in tissues: Therapeutic potential, Toxicol Appl Pharmacol 59, 164-171 (1981)

139) LB Sasser, GG Hall, GR Bratton and J Zmudzki: Absorption and tissue distribution of lead in thiaminreplete and thiamin deficient rats. J Nutr 114, 18161825 (1984)

140) SJS Flora and RP Sharma: Influence of dietary supplementation with thiamin on lead intoxication in rats. Biol Trace Elem Res 10, 137-144 (1986)

141) JH Cheong, DO Seo, JR Ryu, C Shin, YT Kim, HC Kim and KH Ko: Lead induced thiamine deficiency in the brain decreased the threshold of electroshock in rat. Toxicology 133, 105-113 (1999)

142) KS Ghazaly: Influence of thiamin on lead intoxication, lead deposition in tissues and lead haematological response of Tilapia Zillii. Comp Biochem Physiol 100c, 417-421 (1999)

143) Y Ito, M Sasaki, Y Ohka, T Shimohara and I Ishiguro: Effect of thiamin on lead excretions into the bile using rat perfusion experiment. Jpn J Clin Chem 10, 185189 (1986)

144) Y Ito, Y Niiya, M Otani and S Shima: Effect of thiamin on the excretion of sub-cutaneously ingested lead in rat, Toxicol Lett 37, 221-228 (1987)

145) AB Fischer, C Hess, T Neubauer and T Eikmann: Testing of chelating agents and vitamins against lead toxicity using mammalian cell cultures. Analyst 123, 55-58 (1998)

146) SJS Flora and SK Tandon: Adjuvants for therapeutic chelating drugs in lead intoxication. Trace Elem Electr 12, 131-140 (1995)

147) SJS Flora, S Singh and SK Tandon: Chelation in Metal Intoxication XVIII: Combined effects of thiamine and calcium disodium versenate on lead toxicity. Life Sci 38, 67-71 (1986)

148) SJS Flora, SC Pant and AS Sachan: Mobilisation and distribution of lead over the course of combined treatment with thiamin and meso 2, 3 dimercaptosuccinic acid or 2, 3-dimercaptopropane 1sulfonate in experimental lead intoxication in rats. Clin Chem Enzymol Commun 6, 207-216 (1994)

149) JS Kim, EC Crichlow, BR Blakley and CG Rousseaux: The effects of thiamin on the neuropsychological alterations induced by lead. Vet Hum Toxicol 32, 101-
105 (1994)

150) SJS Flora, S Singh and SK Tandon: Chelation in Metal Intoxication XVIII: Combined effects of thiamin and calcium disodium versenate on lead toxicity. Life Sci 38, 67-71 (1986)

151) BD Kumar, MM Khan and K Krishnaswamy: Therapeutic potential of thiamin in lead toxicity. Ind $\mathrm{J}$ Pharmacol 26, 277-281 (1994)

152) JA Simon and ES Hudes: Relationship of ascorbic acid to blood leads levels. JAMA 281, 2289-2293 (1999)

153) DKN Houston, and MA Johnson: Does vitamin C intake protect against lead toxicity? Nutr Rev 58, 7379 (2000).

154) M Dhawan, DN Kachru and SK Tandon: Influence of thiamin and ascorbic acid supplementation on antidotal efficacy of thiol chelators in lead intoxication, Arch Toxicol 62, 301-304 (1988)

155) SJS Flora and SK Tandon: Prevention and therapeutic effects of thiamin, ascorbic acid and their combination in lead intoxication. Acta Pharmacol Toxicol 58, 374378 (1986)

156) RA Goyer, MG Cherian, MM Jones and JR Reigart: Role of chelating agents for prevention, intervention and treatment of exposure to toxic metals. Environ Health Perspect 103, 1048-1052 (1995)

157) B Halliwell, M Wasil and M Grootveld: Biologically significant scavenging of the myeloperoxidase- derived oxidant hypochlorous acid by ascorbic acid. FEBS Lett 213, 15-17 (1987)

158) S Bhadauria and SJS Flora: Arsenic induced inhibition of delta-aminolevulinate dehydratase activity in rat blood and its response to meso-2, 3-dimercaptosuccinic acid and mono-isoamyl DMSA. Biomed Environ Sci 17, 305-313 (2003)

159) S Bhadauria and SJS Flora: Combined administration of thiol chelators on arsenic mobilization and tissue oxidative stress in chronic arsenic exposed male rats. J Tissue Research 4, 95-100 (2004)

160) JB Besunder, DM Super and RL Anderson: Comparison of dimercaptosuccinic acid and calcium disodium ethylenediaminetetraacetic acid versus dimercaptopropanol and ethylenediaminetetraacetic acid in children with lead poisoning. J Pediatr 130, 966-971 (1997).

161) SJS Flora: Nutritional components modify metal absorption, toxic response and chelation therapy. J Nutri Env Med 12, 53-67 (2002)

162) OA Levander, VC Morris and RJ Ferretti: Comparative effects of selenium and vitamin-E in lead poisoned rats. J Nutr 107, 378-382 (1977)

163) DP Jones, VE Kagan, SD Aust, DJ Reed and ST Omaye: Impact of nutrients on cellular lipid peroxidation and antioxidant defence system. Fund Appl Toxicol 26, 1-7 (1995)

164) B Halliwell: Free radicals and antioxidants: a personal view. Nutr Rev 52, 253-265 (1994)

165) OA Levander: Lead toxicity and nutritional deficiencies. Environ Health Perspect 29, 115-125 (1979)

166) Mahaffey KR, Michaelson JA: Interactions between 
lead and nutrition. In: HL Needleman, ed. Low level of lead exposure. The clinical implication of current research. New York: Raveen Press, 1980: 159-200.

167) R Lauwerys, H Roels and JP Buchet: The influence of orally administered vitamin $\mathrm{C}$ or zinc on the absorption of and the biological response to lead. J Occup Med 25, 668-678 (1983)

168) A Sohler, M Kruesi and CC Pfeiffer: Blood lead levels in psychiatric outpatients reduced by zinc and vitamin C. Orthololcul Pschiatr 6, 272-276 (1977)

169) JA Simon and ES Hudes: Relationship of ascorbic acid to blood leads levels. JAMA 281, 2289-2293 (1999)

170) S Chattopadhya, S Ghosh, J Debnath and D Ghosh: Protection of sodium arsenite-induced toxicity by coadministration of L-ascorbate (vitamin C) in mature wistar strain rat. Arch Environ Contam Toxicol 41, 8389 (2001)

171) GS Shukla, T Hussain and SV Chandra: Protective effect of vitamin $\mathrm{E}$ on cadmium induced alterations in lipofuscin and superoxide dismutase in rat brain regions. Pharmacol Toxicol 63, 305-306 (1988)

172) OA Levander, VC Morris and RJ Ferretti: Effect of cell age on the filterability of erythrocyte from vitaminE deficient lead poisoned rats. J Nutr 108, 145-151 (1978)

173) OA Levander, VC Morris and RJ Ferretti: Filterability of erythrocyte from vitamin-E deficient rats. J Nutr 107, 363- 372 (1977)

174) GR Buetter: The pecking order of free radicals and antioxidants: lipid peroxidation, $\alpha$-tocopherol and ascorbate, Arch Biochem Biophys 300, 535-543 (1993)

175) Machlin LJ, Brin M: Vitamin E. In: Alfin-Slater RB, Kritchevsky D, eds. Human nutrition, a comprehensive treatise, nutrition and the adult micronutrients. Plenum Press. New York, 1988: 38: 245-267.

176) GW Burton and KU Ingold: Vitamin E: application of principles of physical organic chemistry to the exploration of its structure and function. Acc Chem Res 19, 194-201 (1986)

177) H Gurer and N Ercal: Can antioxidants be beneficial in the treatment of lead poisoning? Free Radical Biol Med 29, 927-945 (2000)

178) P Weber, A Bendich and LJ Machlin: Vitamin E and human health: rationale for determining recommended intake levels. Nutrition 13, 450-460 (1997)

179) TC Lee and IC Ho: Modulation of cellular antioxidant defense activities by sodium arsenite inhuman fibroblasts. Arch Toxicol 69, 498-504 (1994)

180) SO Welsh and JH Sores Jr: The protective effect of vitamin $\mathrm{E}$ and selenium against methylmercury toxicity in the Japanese quail. Nutr Rep Int 13, 43-48 (1978).

181) HE Ganther: Modification of methyl mercury toxicity and metabolism by selenium and vitamin E: possible mechanisms. Environ Health Perspect 25, 71-76 (1978)

182) OA Levander, VC Morris, DJ Higgs and RJ Ferretti: Lead poisoning in vitamin-E deficient rats. J Nutr 105, 1481-1485 (1975)

183) GM Kannan and SJS Flora: Combined administration of Meso 2,3-dimercaptosuccinic acid (DMSA) or Monoisoamyl DMSA with an antioxidant for the treatment of chronic experimental arsenic poisoning in rats. Ecotoxicol Environ Safety 58, 37-43 (2004)

184) OI Aruoma, B Halliwell and J Butler: The antioxidant action of n-acetylcysteine in reaction wit hydrogen peroxide, hydroxy radical, superoxide and hypochlorous acid. Free Radic Biol Med 6, 593-597 (1989)

185) H Ottenwalder and P Simon: Differential effect of Nacetyl cysteine on excretion of the metals $\mathrm{Hg}, \mathrm{Cd}, \mathrm{Pb}$ and Au. Arch Toxicol 60, 401-402 (1987)

186) SJS Flora: Arsenic induced oxidative stress and its reversibility following combined administration of $\mathrm{N}$ acetyl cysteine and meso 2, 3-dimercaptosuccinic acid in rats. Clin Exp Pharmacol Physiol 26, 865-869 (1999)

187) SJS Flora, M Pande, GM Kannan and A Mehta: Lead induced oxidative stress and its recovery following coAdministration of Melatonin or N-Acetylcysteine during chelation with Succimer in male rats. Cell Mol Biol 50, OL543-OL551(2004)

188) RJ Reiter: Interactions of the pineal hormone melatonin with oxygen - centered free radicals. A brief review. Braz J Med Biol Res 26, 1141-1155 (1993)

189) RJ Reiter, RCG Carneiro and CS Oh: Melatonin in relation to cellular antioxidative defense mechanisms. Horm Metab Res 29, 343-392 (1997)

190) RJ Reiter, DX Tan, D Poeggeler, A Mendez-Pelaez, LD Chen, and S Saarela: Melatonin as a free radical scavenger: implications for ageing and aged-related diseases. An NY Acad Sci 719, 1-12 (1994)

191) R Hardeland, RJ Reiter, B Poeggeler and DX Tan: The significance of the metabolism of the neurohormone melatonin: antioxidative protection and formation of bioactive substances. Neurosci Biobehav Rev 17, 347 357 (1993)

192) RJ Reiter: Functional aspects of pineal hormone melatonin in combating cell and tissue damage induced by free radicals. Eur J Endocrinol 134, 412-420 (1996)

193) DX Tan, LD Chen, B Poeggeler, LC Manchester and RJ Reiter: Melatonin: a potent endogenous hydroxyl radical scavenger. Endocrinol J 1, 57-60 (1993)

194) LR Barlow-Walden, RJ Reiter, M Abe, M Pablos, A Menendez-Pelaes, LD Chen and B Poeggeler: Melatonin stimulates brain Glutathione Peroxidase activity. Neurochem Int 26, 15-21 (1995)

195) E Sewerynek, D Melchiorri, RJ Reiter, GG Ortiz and A Lewinsky: Lipopolysaccharide- induced hepatotoxicity is inhibited by the antioxidant melatonin. Eur J Pharmacol 293, 327-334 (1995)

196) D Melchiorri, RJ Reiter, AM Attia, M Hara, A Burgos and G Nistico: Potent protective effect of melatonin on in vivo paraquat- induced oxidative damage in rats. Life Sci 56, 83-89 (1994)

197) RT Blinkenstaff, SM Brandstadter, S Reddy and R Witt: Potential radio protective agents. 1. Homologues of melatonin. J Pharm Sci 83, 216-218 (1994)

198) E Sewerynek, D Melchiorri, RJ Reiter, GG Ortiz and A Lewinsky: Oxidative damage in the liver induced by ischemia- reperfusion: protection by melatonin. Hepato Gastroenter 43, 898-905 (1996)

199) EJX Costa, RH Lopes and MT Lamy-Freund: 
Permeability of pure lipid bilayers of melatonin. J Pineal Res 19, 123-126 (1995)

200) EJ Costa, CS Shida, MH Biaggi, AS Ito and MT LamyFreund: How melatonin interacts with lipid bilayers: a study by fluorescence and ESR spectroscopies. FEBS Lett 416, 103-106 (1977)

201) CS Shida, AML Castrucci and MT Larmy-Freund: High melatonin solubility in aqueous medium. J Pineal Res 16, 198-201 (1994)

202) H Gurer, H Ozgunes, S Oztezcan and N Ercal: Antioxidant role of $\alpha$-lipoic acid in lead toxicity. Free Radic Biol Med 29, 927-945 (1999)

203) LJ Reed: Multienzyme complexes. Acc Chem Res 7, 40-46 (1974)

204) JP Carreau: Biosynthesis of lipoic acid via unsaturated fatty acids. Methods Enzymol 62, 152-158 (1979)

205) L Packer, EH Witt and HJ Tritschler: Alpha lipoic acid as a biological antioxidant. Free Rad Biol Med 19, 227250 (1995)

206) M Panigrahi, Y Sadguna, BR Shivkumar, SVR Kolluri, R Sashwati, L Packer and V Ravindranath: Lipoic acid protects against reperfusion injury following cerebral ischemia in rats. Brain Res 717, 184-188 (1996)

207) M Pande and SJS Flora: Lead induced oxidative damage and its response to combined administration of $\alpha$-lipoic acid and DMSA in rats. Toxicology 177, 187-196 (2002)

208) CE Wright, HH Tallan and YY Linn: Taurine: Biological update. Ann Rev Biochem 55, 427-453 (1986)

209) Davis JM, Harwich WA. Amino acids and proteins of developing brain. In: Biochemistry of the developing brain edited by Harwich, WA. New York: Decker, 1973: 55-110.

210) RJ Hittable: Physiological action of taurine. Physiol Rev 72, 101-63 (1992)

211) SJS Flora, M Pande, S Bhadauria and GM Kannan: Combined administration of taurine and meso 2,3dimercaptosuccinic acid in the treatment of chronic lead intoxication in rats. Human Exp Toxicol 23, 157-166 (2004)

212) P Mandy, G Talker and A Sharma: Dietary factors in cancer chemoprevention. The Nucleus 40: 128-144 (1997)

213) Richa and SJS Flora: Protective Value of Aloe Vera against some toxic effects of arsenic in rats. Phototherapy Res, In Press (2004).

214) A Rouse: The genus Hippophae L., a taxonomic study.
An Botany Fen 8, 177-227 (1971)

215) JS Chen, MP Gatchis, CT Campbell and GF Combs: Effects of dietary selenium and vitamin $\mathrm{E}$ on hepatic mixed-function oxidize and in vivo covalent binding of aflatoxin B1 in rats. J Nutr 112, 324-331 (1982)

216) H Kallio and B Yang and P Peippo: Effects of different origins and harvesting time on vitamin $\mathrm{C}$, tocopherol, and tocotrienols in Sea buckthorn (hippophae rhammoides) berries. J Agri Fd Chem 50, 6136-6142 (2002)

217) C Eccleston, Y Baoru, R Tahvonen, H Kallio, GH Rimbach and AM Minihene: Effects of an antioxidant rich juice (sea buckthorn) on risk factors for coronary heart disease in humans. J Nutr Biochem 13, 346-354 (2002)

218) S Geetha, M Sai Ram, SS Mongia, V Singh, G Ilavazhagan and RC Sawhney: Evaluation of antioxidant activity of leaf extract of Seabuckthorn (Hippophae rhamnoides L.) on chromium induced oxidative stress in albino rats. J Ethanopharmacol 87, 247-251 (2003)

219) S Geetha, M Sai Ram, V Singh, G Ilavazhagan and RC Sawhney: Antioxidant and immunomodulatory properties of Seabuckthorn (Hippophae rhamnoides L.): an in vitro study. J Ethanopharmacol 79, 373-378 (2002)

220) G Grindlay and T Reynolds T: The Aloe vera phenomenon. A review of the properties and modern uses of the leaf parenchyma gel. J Ethnopharmacol 16, 117-151 (1980)

221) T Reynolds and AC Dweck: Aloe vera leaf gel: a review update. J Ethanopharmacol 68, 3-37 (1999)

222) P Chithra, GB Sajithlal and G Chandrakasan: Influence of Aloe vera on the glycosaminoglycans in the matrix of healing dermal wounds in rats. J Ethanopharmacol 59, 179-186 (1998)

223) GS Shukla and SV Chandra: Cadmium toxicity and bioantioxidants status of vitamin $\mathrm{E}$ and ascorbic acid of selected organs in rats. J Appl Toxicol 9, 119-122 (1989)

224) L Suguna, P Sivakumarm and G Chandrakasan: Effects of Centella asiatica extract on dermal wound healing in rats. Ind J Exp Biol 34, 1208-1211 (1996)

225) Vaidyaratnam PSV. Indian medicinal plant: A compendium of 500 species, Vol. 2, Orient Longman Ltd., Anna Salai, Madras, India, 52: 1994.

226) P Kakkar: Mandukparni- medicinal uses and therapeutic efficacy. Probe XXIX 196-182 (1990) 